\title{
Rare Earth Elements Geochemistry and Nd Isotopes in the Mississippi River and Gulf of Mexico Mixing Zone
}

\author{
Segun B. Adebayo ${ }^{1 *}$, Minming Cui ${ }^{1}$, Travis Hong ${ }^{1}$, Christopher D. White ${ }^{1}$, Ellen E. Martin ${ }^{2}$ \\ and Karen H. Johannesson ${ }^{1}$ \\ ${ }^{1}$ Department of Earth and Environmental Sciences, Tulane University, New Orleans, LA, United States, ${ }^{2}$ Department of \\ Geological Sciences, University of Florida, Gainesville, FL, United States
}

\section{OPEN ACCESS}

Edited by:

Selvaraj Kandasamy,

Xiamen University, China

Reviewed by:

Waliur Rahaman

National Centre for Antarctic and

Ocean Research, India

Nagender Nath Bejugam,

National Institute of Oceanography

(CSIR), India

Armstrong-Altrin John S.

Universidad Nacional Autónoma de

México, Mexico

*Correspondence:

Segun B. Adebayo

sadebay@tulane.edu

Specialty section:

This article was submitted to

Marine Biogeochemistry,

a section of the journal

Frontiers in Marine Science

Received: 05 December 2017

Accepted: 25 April 2018

Published: 16 May 2018

Citation:

Adebayo SB, Cui M, Hong T,

White $C D$, Martin EE and

Johannesson KH (2018) Rare Earth

Elements Geochemistry and Nd Isotopes in the Mississippi River and

Gulf of Mexico Mixing Zone.

Front. Mar. Sci. 5:166.

doi: 10.3389/fmars.2018.00166
Rare earth elements (REE) concentrations were measured in surface waters collected across the salinity gradient in the Mississippi River estuary (i. e., Mississippi River plume, MRP), which includes the near-shore portion of the Louisiana Shelf. In addition, the neodymium ( $\mathrm{Nd}$ ) isotope compositions of two river water samples, and the acid leachable fractions of the associated suspended particulate matter (SPM), were quantified to compare Mississippi River water, and SPM with Gulf of Mexico waters. Despite the spatial limitations associated with sampling due to the size of the Mississippi River system, this study provides some important insights into the REE geochemistry of the MRP. The Mississippi River and its estuarine waters are enriched in the heavy REE (HREE) compared to the light REE (LREE) when normalized to shale composites. All water samples from the estuary also exhibit substantial negative Ce anomalies. In contrast to the majority of other estuaries investigated, removal of REE in the low salinity reaches of the Mississippi River estuary is less substantial. For example, approximately $50 \%$ of the river borne $\mathrm{Nd}$ is removed in the low salinity region $(S<10)$ of the Mississippi River estuary, compared to the estimated global average of ca. $70 \%$ removal of $\mathrm{Nd}$ for estuaries worldwide. We propose that the relatively low REE removal in the Mississippi estuary reflects the high $\mathrm{pH}(\sim 8)$ of the Mississippi River, where REE complexation with carbonate ions and natural organic ligands act to stabilize REE in solution. The Nd isotope composition of Mississippi River water near its outflow to the Gulf of Mexico is $\varepsilon_{\mathrm{Nd}(0)}=$ -10.5 . The acid leachable fraction of the associated SPM is more radiogenic $(-9.95$ $\left.\leq \varepsilon_{\mathrm{Nd}(0)} \leq-9.77\right)$, and closer to the generally more radiogenic Gulf of Mexico $\left[\varepsilon_{\mathrm{Na}(0)}=\right.$ -9.0]. Sequential extraction of the Mississippi River bank sediment reveals substantially different $\mathrm{Sm} / \mathrm{Nd}$ ratios for the operationally defined fractions of the sediment, which suggests variations in $\mathrm{Nd}$ isotope compositions between the labile fractions and the bulk sediment.

Keywords: Mississippi River, rare earth elements, Nd isotopes, estuary, Gulf of Mexico

\section{INTRODUCTION}

Rivers, followed by atmospheric deposition, are considered the chief sources of rare earth elements (REE), and hence neodymium (Nd), to the ocean (Goldstein et al., 1984; Tachikawa et al., 2003). The REE and Nd isotopes are applied in tracing biogeochemical processes, and past/modern ocean circulation, hence, the need to better understand REE speciation and mass transfer between 
major rivers and the ocean. Estuaries are the interface between rivers and the ocean, wherein REE compositions of rivers undergo substantial transformation. This non-conservative behavior of REE in estuaries is commonly attributed to sea salt induced coagulation of colloids (Edzwald et al., 1974; Elderfield et al., 1990; Sholkovitz and Szymczak, 2000; Rousseau et al., 2015). However, other complex processes are increasingly reported to exert important controls over mass transfer to the oceans. These processes include: (1) "boundary exchange", shallow pore water fluxes, and submarine groundwater discharge (SGD) acting along ocean-continent margins; (2) pore water fluxes in the deep ocean; and (3) reversible scavenging with sinking particles, in the water column (Lacan and Jeandel, 2001; Johannesson and Burdige, 2007; Abbott et al., 2015; Du et al., 2016; Jeandel, 2016). Sorting out the relative importance of these processes to mass fluxes in the ocean remains a daunting challenge.

The application of $\mathrm{Nd}$ isotopes in tracing oceanic water mass circulation is limited by the relatively poor constraints on $\mathrm{Nd}$ sources and sinks in the ocean (Lacan and Jeandel, 2001; Goldstein and Hemming, 2003; Jeandel et al., 2007; Jeandel and Oelkers, 2015). Related to this is the so-called "Nd paradox," which is the apparent decoupling of dissolved $\mathrm{Nd}$ concentrations and $\mathrm{Nd}$ isotopes (Lacan and Jeandel, 2001; Goldstein and Hemming, 2003; Tachikawa et al., 2003; Siddall et al., 2008; Arsouze et al., 2009). Specifically, Nd concentrations have nutrient-like water column profiles suggestive of vertical cycling and relatively long, ca. $10^{4}$ years, oceanic residence times, whereas $\mathrm{Nd}$ isotope ratios exhibit inter- and intra-ocean differences, which supports an oceanic $\mathrm{Nd}$ residence time similar to $<500-1,500$ years. Hence, more quantitative spatial and temporal understanding of the sources and sinks of the REE in the ocean is required to resolve the Nd paradox, which includes better understanding of the dynamics of REE in estuaries.

The lower Mississippi River and its associated estuary is an ideal location to investigate the importance of riverine REE fluxes from a major world river that debouches over a broad, shallow continent-ocean margin, where "boundary exchange" may be important. This is because the Mississippi River is the chief source of freshwater and sediment to the Gulf of Mexico (Trefry and Shokes, 1981), which is a partially closed ocean basin that is characterized by an extensive continent-ocean margin (ca. 33\% of area). Prior studies of the Mississippi River system have looked at the REE geochemistry at locations distant from its mixing zone with the Gulf of Mexico. These previous studies provide important insights, such as compositions of the $\mathrm{REE}$ in the river water, suspended particulate matter, and $\mathrm{Nd}$ isotopic compositions of the phases (e.g., Goldstein and Jacobsen, 1988a,b; Sholkovitz, 1995; Shiller, 2002; Bayon et al., 2015), coupled with temporal variations in the REE compositions of the river water (Shiller, 2002). Although it seems likely that the Mississippi River is a substantial source of REE to the Gulf of Mexico, and especially the northern and eastern Gulf, there have been no systematic investigations of the REE or $\mathrm{Nd}$ isotopes in its associated estuary. Consequently, there is a need to ascertain the importance of the Mississippi River water and/or sediment as source(s) of REE to the Gulf of Mexico.
Here, we present new REE and $\mathrm{Nd}$ isotope data for waters, suspended particulate matter (SPM), and riverbank sediment from the lower Mississippi River and its associated estuary (i.e., Mississippi River plume; MRP) on the Louisiana Shelf. These data are employed to probe the geochemical processes that influence the transfer of REE from the Mississippi River to the Gulf of Mexico, in an effort to begin to assess the importance of the river on the REE and Nd isotope systematics of the Gulf.

\section{STUDY SITE}

The study site along the lower Mississippi River and its associated estuary on the Louisiana Shelf is shown in Figure 1. The Mississippi River is the seventh largest river in the world in terms of both water and sediment discharge to the ocean, and is the largest river draining North America, with sediment and water discharges of $210 \times 10^{6}$ tons year ${ }^{-1}$ and $530 \times 10^{9} \mathrm{~m}^{3}$ year $^{-1}$, respectively (McKee et al., 2004). During high flow periods, which commonly occur in spring and early summer, discharge from the Mississippi River mouth is great enough to form a stratified estuary over the Louisiana Shelf (i.e., the MRP), whereas during low discharge, a partially mixed salt wedge estuary forms within the distributary channels of the river, in the birdfoot delta (Shiller and Boyle, 1991). The differences in seasonal discharge typically lead to highly variable spatial salinity distributions in the Mississippi River estuary and Louisiana Shelf. Most of the Mississippi River discharge reaches the Gulf of Mexico through three major distributaries in the birdfoot delta: Pass á Loutre, Southwest Pass, and South Pass (Shiller and Boyle, 1991). The samples reported in this study were collected along the Southwest Pass and out into the Louisiana Bight of the Gulf of Mexico. The Southwest Pass was chosen for this study because it empties westward along the Louisiana-Texas shelf, where approximately $50 \%$ of the Mississippi River's discharge flows (Bianchi et al., 2010).

\section{METHODS}

\section{Sample Collection}

Water sampling was done using Teflon ${ }^{\circledR}$ tubing via a peristaltic pump and transferred into high-density polyethylene (HDPE) sample bottles, all of which were pre-cleaned following trace metal cleaning procedures (e.g., Johannesson et al., 2004). A total of 15 water samples were collected for analysis of REE concentrations. Thirteen water samples from the Louisiana Bight (labeled 0-10, Figure 1; Table 1), which include 9 surface water samples $(\sim 1 \mathrm{~m}$ depths), and 4 deeper water samples $(>6 \mathrm{~m}$ depths) from two locations (labeled 6 and 10, Figure 1; Table 1), were collected in June 2014. Two "fresh" (salinity, $S \approx 0$ ) Mississippi River water and SPM samples were collected in January 2016, for REE concentrations and $\mathrm{Nd}$ isotopes analyses. Both river water samples are labeled "MR" in Figure 1, with one collected in the river channel, whereas the second water sample was obtained nearby, from a crevasse where the river spills across its natural levee into Breton Sound. The water samples were filtered through $0.45 \mu \mathrm{m}$ Gelman Sciences (polysulfone ether membrane) high capacity filters during sample collection. 


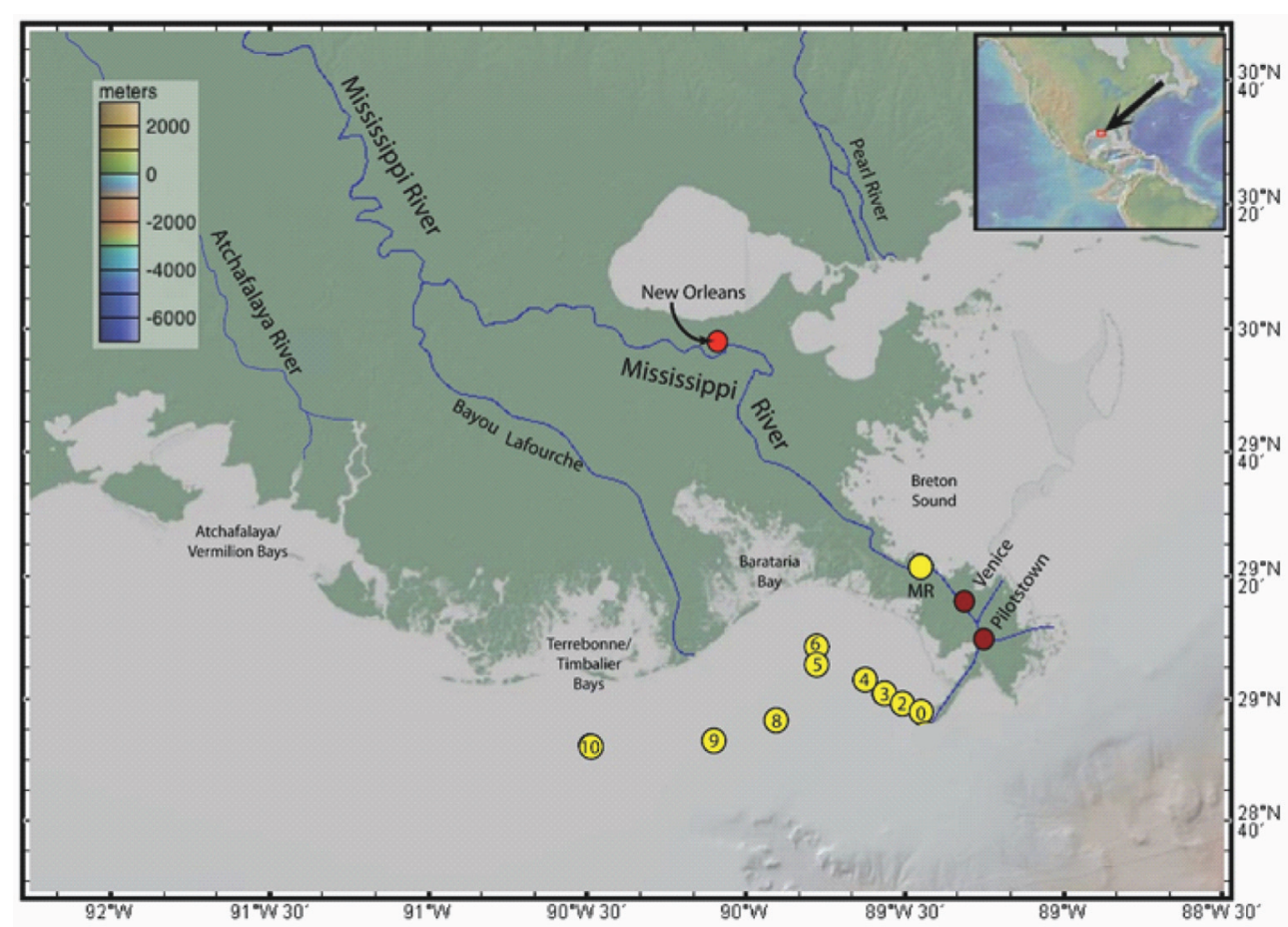

FIGURE 1 | Lower Mississippi River delta showing the sampling locations of waters (yellow circles), SPM (yellow circle labeled "MR"), and sediment (bright red circle labeled "New Orleans"). The dark red circles labeled "Venice" and "Pilotstown" show the locations of the earlier $\varepsilon_{\mathrm{Nd}(0)}$ measurements by Stordal and Wasserburg (1986). Atchafalaya River and Bayou Lafourche are major and minor, respectively, distributaries of the MR. Base map from GeoMapApp.

The filter capsules were transferred to clean zip-lock ${ }^{\circledR}$ style polyethylene bags for analysis of the SPM collected by the filter membrane.

The filtered water samples were returned to the laboratory where they were acidified inside a class 100 (ISO 5 rated) clean room to $\mathrm{pH}<2$ with ultrapure $\mathrm{HNO}_{3}$ (Thermo Fisher Optima $^{\mathrm{TM}}$ ) within $24 \mathrm{~h}$ of collection. Acidification is to prevent iron and manganese oxide/oxyhydroxide precipitation, and adsorption losses of the REE to the sample bottle walls. In addition to the water samples, a sediment sample was collected from the Mississippi River bank at New Orleans (labeled "New Orleans"; Figure 1), for analysis of total REE contents and by sequential extraction. The sediment sample was collected by grab sampling into clean zip-lock ${ }^{\circledR}$ style polyethylene plastic bags for transport to the laboratory where it was oven dried at $\mathrm{ca} .80^{\circ} \mathrm{C}$ and stored prior to analysis.

\section{Sample Analysis}

Sample preparation procedures for all analyses in this study were performed within a Class 100 (ISO 5 rated) laminar flow clean bench and/or clean laboratory. Major cations $\left(\mathrm{Ca}^{2+}, \mathrm{Mg}^{2+}, \mathrm{Na}^{+}\right.$, $\mathrm{K}^{+}$) concentrations in Mississippi River water were analyzed on acidified samples by high resolution inductively coupled plasma mass spectrometry (HR-ICP-MS; Thermo Fisher Element II), as described previously (Chevis et al., 2015; Johannesson et al., 2017). Anion concentrations $\left(\mathrm{Cl}^{-}, \mathrm{SO}_{4}^{2-}, \mathrm{NO}_{3}^{-}, \mathrm{F}^{-}\right)$were determined in unacidified river water samples by Dr. Susan Welch via ion chromatography (Dionex DX-3000) at Ohio State
University, following the approach of Welch et al. (1996). The temperature, dissolved oxygen concentrations, turbidity, and salinity of the Mississippi River estuary samples were determined on-site using a Seabird SBE 19+ v2 multi-meter, whereas $\mathrm{pH}$ was measured using a waterproof double junction pHTestr ${ }^{\circledR} 30 \mathrm{pH}$ electrode.

Mississippi River and estuary waters were analyzed for REE using pre-established methods (e.g., Johannesson et al., 2011, 2017; Chevis et al., 2015). Aliquots (30 mL) of the filtered and acidified water samples were loaded onto Bio-Rad ${ }^{\circledR}$ Poly-Prep columns packed with $\sim 2 \mathrm{~mL}$ of Bio-Rad ${ }^{\circledR}$ AG 50W-X8 (200-400 mesh, hydrogen form) cation exchange resin. Prior to loading, the columns were pre-cleaned using alternating $10 \mathrm{~mL}$ rinses of $6 \mathrm{M}$ ultra-pure hydrochloric acid $(\mathrm{HCl})$ and Millipore-Q water $(18.2 \mathrm{M} \Omega \mathrm{cm})$. After loading the samples on the columns, Fe and $\mathrm{Ba}$ were sequentially eluted from the columns by rinsing, first with $3 \mathrm{~mL}$ of $1.75 \mathrm{M}$ ultra-pure $\mathrm{HCl}$, followed by $3 \mathrm{~mL}$ of $2 \mathrm{M}$ ultra-pure $\mathrm{HNO}_{3}$ (Greaves et al., 1989). The REE were then eluted from the columns using $10 \mathrm{~mL}$ of $8 \mathrm{M}$ ultrapure $\mathrm{HNO}_{3}$, and collected into pre-cleaned Teflon ${ }^{\circledR}$ beakers. The REE eluents were subsequently evaporated to near dryness and then re-dissolved in $10 \mathrm{~mL}$ of $1 \%(\mathrm{v} / \mathrm{v})$ ultrapure $\mathrm{HNO}_{3}$ solution. Aliquots $(30 \mathrm{~mL})$ of the National Research Council Canada (Ottawa, Canada) Standard Reference Material (SRM) for estuarine waters (SLEW-3) were also loaded onto identical columns, as were $30 \mathrm{~mL}$ aliquots of Millipore-Q water, which acted as analytical blanks (e.g., Johannesson et al., 2017). The column separation converted the original $30 \mathrm{~mL}$ sample aliquot 
TABLE 1 | Field parameters characterizing the Mississippi River and estuary water samples, with individual sampling location and collection depth.

\begin{tabular}{|c|c|c|c|c|c|c|c|c|}
\hline Sampling point no. ${ }^{¥}$ & Latitude & Longitude & Sample Depth (m) & Temp $\left({ }^{\circ} \mathbf{C}\right)$ & Salinty & $\mathrm{DO}\left(\mathrm{mmol} \mathbf{k g}^{-1}\right)$ & Turbidity (NTU) & $\mathrm{pH}$ \\
\hline MR & $29^{\circ} 21.463^{\prime} \mathrm{N}$ & $89^{\circ} 26.461^{\prime} \mathrm{W}$ & $\sim 1$ & - & 0 & - & - & 7.8 \\
\hline 0 & $28^{\circ} 58.156^{\prime} \mathrm{N}$ & $89^{\circ} 25.820^{\prime} \mathrm{W}$ & 1.3 & 28.0 & 8.2 & 0.26 & 54.5 & 8.1 \\
\hline 2 & $28^{\circ} 59.104^{\prime} \mathrm{N}$ & $89^{\circ} 30.211^{\prime} \mathrm{W}$ & 1.3 & 29.8 & 22.8 & 0.22 & 1.1 & 8.3 \\
\hline 3 & $29^{\circ} 00.668^{\prime} \mathrm{N}$ & $89^{\circ} 33.842^{\prime} \mathrm{W}$ & 1.1 & 29.6 & 22.6 & 0.22 & 28.7 & 8.4 \\
\hline 4 & $29^{\circ} 03.164^{\prime} \mathrm{N}$ & $89^{\circ} 37.448^{\prime} W$ & 1.2 & 29.6 & 20.9 & 0.21 & 39.9 & 8.4 \\
\hline 5 & $29^{\circ} 05.951^{\prime} \mathrm{N}$ & $89^{\circ} 46.504^{\prime} \mathrm{W}$ & 1.4 & 29.3 & 21.4 & 0.21 & 50.0 & 8.4 \\
\hline $6 a$ & $29^{\circ} 08.564^{\prime} \mathrm{N}$ & $89^{\circ} 46.462^{\prime} \mathrm{W}$ & 17.5 & 24.4 & 36.0 & 0.05 & 7.5 & 7.8 \\
\hline $6 b$ & $29^{\circ} 08.564^{\prime} \mathrm{N}$ & $89^{\circ} 46.462^{\prime} W$ & 6.2 & 28.1 & 31.4 & 0.16 & 40.3 & 8.1 \\
\hline $6 c$ & $29^{\circ} 08.564^{\prime} \mathrm{N}$ & $89^{\circ} 46.462^{\prime} \mathrm{W}$ & 0.8 & 29.2 & 19.8 & 0.22 & 44.6 & 8.4 \\
\hline 8 & $28^{\circ} 56.470^{\prime} \mathrm{N}$ & $89^{\circ} 54.109^{\prime} \mathrm{W}$ & 1.2 & 30.1 & 22.4 & 0.21 & 83.5 & 8.5 \\
\hline 9 & $28^{\circ} 53.162^{\prime} \mathrm{N}$ & $90^{\circ} 05.988^{\prime} \mathrm{W}$ & 1.3 & 30.2 & 23.1 & 0.22 & 39.8 & 8.5 \\
\hline $10 a$ & $28^{\circ} 52.284^{\prime} \mathrm{N}$ & $90^{\circ} 29.326^{\prime} \mathrm{W}$ & 16.8 & 23.6 & 35.7 & 0.04 & 5.7 & 7.8 \\
\hline $10 b$ & $28^{\circ} 52.284^{\prime} \mathrm{N}$ & $90^{\circ} 29.326^{\prime} W$ & 11.1 & 24.9 & 34.4 & 0.11 & 18.4 & 8.0 \\
\hline 10c & $28^{\circ} 52.284^{\prime} \mathrm{N}$ & $90^{\circ} 29.326^{\prime} W$ & 1.5 & 29.5 & 27.5 & 0.21 & 36.3 & 8.3 \\
\hline
\end{tabular}

$¥$ Numbers correspond to those given on Figure 1 .

to a final volume of $10 \mathrm{~mL}$, producing a 3-fold increase in REE concentrations in the solutions introduced to the HR-ICP-MS, which in effect lowered the detection limit by a factor of $\sim 3$ for each REE.

Prior to analysis, each $10 \mathrm{~mL}$ concentrated aliquot was spiked with ${ }^{115}$ In (at $1 \mu \mathrm{g} \mathrm{kg}^{-1}$ ), as an internal standard. To minimize various polyatomic, oxide/hydroxide, and other mass interferences, multiple resolution configurations were used on the HR-ICP-MS (Chevis et al., 2015). The REE isotopes monitored at various resolutions are as follows: ${ }^{139} \mathrm{La},{ }^{140} \mathrm{Ce}$, ${ }^{141} \mathrm{Pr},{ }^{143} \mathrm{Nd},{ }^{145} \mathrm{Nd},{ }^{146} \mathrm{Nd},{ }^{147} \mathrm{Sm},{ }^{149} \mathrm{Sm},{ }^{151} \mathrm{Eu},{ }^{153} \mathrm{Eu},{ }^{155} \mathrm{Gd}$, ${ }^{157} \mathrm{Gd},{ }^{158} \mathrm{Gd},{ }^{159} \mathrm{~Tb},{ }^{161} \mathrm{Dy},{ }^{163} \mathrm{Dy},{ }^{165} \mathrm{Ho},{ }^{166} \mathrm{Er},{ }^{167} \mathrm{Er},{ }^{169} \mathrm{Tm}$, ${ }^{172} \mathrm{Yb},{ }^{173} \mathrm{Yb}$, and ${ }^{175} \mathrm{Lu}$, at low and high-resolution modes; ${ }^{139} \mathrm{La}$, ${ }^{140} \mathrm{Ce},{ }^{141} \mathrm{Pr},{ }^{143} \mathrm{Nd}$, and ${ }^{145} \mathrm{Nd}$, at low and medium-resolution modes. We also monitored ${ }^{151} \mathrm{Eu},{ }^{153} \mathrm{Eu}$, and the HREE in high-resolution mode to resolve interferences from $\mathrm{BaO}^{+}$and $\mathrm{LREEO}^{+}$species formed in the plasma stream on the two Eu isotopes, and other $\mathrm{REEO}^{+}$species on the HREE. A series of REE calibration standard solutions with concentrations 5, 10, 20, 100,500 , and $1,000 \mathrm{ng} \mathrm{kg}^{-1}$ were prepared from NIST traceable High Purity Standards (Charleston, SC). As an additional check of accuracy, we compared our measured values of the REE for SLEW-3 with those reported by Lawrence and Kamber (2006). The relative standard deviations (RSD) were better than $5 \%$ for the determination of REE in the water samples.

Neodymium isotopic compositions of the Mississippi River water samples (labeled "MR"; Figure 1), as well as acid leachates of the SPM collected on the $0.45 \mu \mathrm{m}$ filters, used for filtering these water samples were determined on a $\mathrm{Nu}$ Instruments multicollector ICP-MS at the University of Florida. The Nd isotopic composition is expressed as epsilon neodymium units, $\varepsilon_{\mathrm{Nd}(0)}$. Epsilon notation is defined as:

$$
\varepsilon_{\mathrm{Nd}(0)}=\left[\frac{\left({ }^{143} \mathrm{Nd} /{ }^{144} \mathrm{Nd}\right)_{\text {measured }}}{\left({ }^{143} \mathrm{Nd} /{ }^{144} \mathrm{Nd}\right)_{\text {CHUR }}}-1\right] \times 10^{4}
$$

in which $\left({ }^{143} \mathrm{Nd} /{ }^{144} \mathrm{Nd}\right)_{\text {measured }}$ is the isotopes ratio measured in the sample and $\left({ }^{143} \mathrm{Nd} /{ }^{144} \mathrm{Nd}\right)_{C H U R}$ is the present day $\mathrm{Nd}$ isotopes ratio (0.512638) for CHUR (Chondritic Uniform Reservoir; Jacobsen and Wasserburg, 1980).

Before transfer to the University of Florida, the freshwater samples ( $3 \mathrm{~L}$ each) were evaporated to near dryness and then diluted to $30 \mathrm{~mL}$ with $2 \% \mathrm{HNO}_{3}$. The filters were leached to obtain the REE concentrations and $\mathrm{Nd}$ isotopic composition of the combined acid leachable fractions (carbonate and/or $\mathrm{Fe} / \mathrm{Mn}$ oxide/oxyhydroxide minerals) following the procedure of Landing and Lewis (1991). Briefly, the filters were leached at room temperature for $4 \mathrm{~h}$ each, first with $20 \mathrm{~mL}$ of $25 \%$ acetic acid, followed by $20 \mathrm{~mL}$ (1:1; volume) mixture of $2 \mathrm{M} \mathrm{HCl} / 1 \mathrm{M}$ $\mathrm{HNO}_{3}$. The leachates were then combined, evaporated to near dryness, and diluted to $30 \mathrm{~mL}$ with $2 \% \mathrm{HNO}_{3}$, prior to analysis for REE concentrations and $\mathrm{Nd}$ isotopic composition.

At the University of Florida, the $30 \mathrm{~mL}$ samples were again evaporated to near dryness, and then diluted with $1 \mathrm{M} \mathrm{HNO}_{3}$, before passing through TruSpec resins to isolate REE, followed by $\mathrm{LnSpec}$ resin to isolate $\mathrm{Nd}$, as modified from Pin and Zalduegui (1997). Procedural blanks of 14 pg Nd, or minimum three orders of magnitude lower than sample abundances were monitored. Samples of isolated $\mathrm{Nd}$ were diluted with $2 \%$ $\mathrm{HNO}_{3}$ to achieve ${ }^{143} \mathrm{Nd}$ monitor peak values of $2-5 \mathrm{~V}$. All samples were analyzed using a desolvating nebulizer (DSN100), and a time-resolved analysis (TRA) method adopted from Kamenov et al. (2008). All ratios were corrected for mass fractionation using ${ }^{146} \mathrm{NdO} /{ }^{144} \mathrm{NdO}=0.7219$. JNdi-1 was run between every 4-5 samples and unknown samples were corrected using the difference between the average of the standard runs and the JNdi-1value of 0.512115 (Tanaka et al., 2000). Long-term external reproducibility of replicate runs of JNdi-1 is \pm 0.000014 ( 2 sigma), which is equivalent to $\pm 0.3 \varepsilon_{\mathrm{Nd}}$ units. This external uncertainty is typically larger than internal uncertainties, and the larger of the two errors is assigned to all samples. 
The REE concentrations in different operationally defined fractions of Mississippi riverbank sediment were investigated using the sequential extraction procedure of Tessier et al. (1979) and detailed in Willis and Johannesson (2011). Briefly, this procedure consisted of five duplicate sequential leaches of the sediment, with each duplicate step targeting the REE composition of an operationally defined fraction of the sediment. The sediment residue following each step served as input for leaching of the subsequent fraction. The sediment residue was separated from the leachate by centrifugation, and rinsed with Millipore$\mathrm{Q}$ water, before the next leaching step. Fraction 1 represents the easily exchangeable fraction, referring to REE sorbed onto the surface of the sediment. Fraction 2 represents the acid labile fraction, referring to the REE content of the carbonate minerals in the sediment. Fraction 3 represents the reducible fraction, referring to the REE content of the Fe/Mn oxides/oxyhydroxides within the sediment. Fraction 4 represents the oxidizable fraction, referring to the REE content of the organic matter and/or sulfide minerals in the sediment. Lastly, fraction 5 represents the residual fraction, referring to the REE content of silicates and framework minerals in the sediment.

\section{Solution Complexation Model}

Solution complexation modeling of the REE concentrations in Mississippi River water was performed using the Windermere Humic Aqueous Model VII (WHAM VII), which includes the latest version of the Humic Ion Binding Model VII (Tipping, 1994; Tipping et al., 2011). WHAM VII was chosen for the REE speciation modeling because: (1) it is able to model REE complexation with both organic and inorganic ligands; (2) the model predictions agree well with the results of ultrafiltration experiments; and (3) sensitivity analysis indicates that the model correctly predicts the impact of changing ionic strength and competing cations (i.e., $\mathrm{Fe}^{3+}, \mathrm{Al}^{3+}$ ) on $\mathrm{REE}$ complexation with natural organic ligands (Tang and Johannesson, 2003; Pourret et al., 2007; Marsac et al., 2017).

For REE complexation with inorganic ligands, the infinite dilution stability constants for the bicarbonate, carbonato, and dicarbonato lanthanide complexes in the WHAM VII default database were replaced with those from Luo and Byrne (2004). In addition, we replaced the following default database stability constants: hydroxyl complexes with those from Klungness and Byrne (2000); sulfate complexes with those from Schijf and Byrne (2004); chloride complexes with those from Luo and Byrne (2001); and fluoride complexes with those from Luo and Byrne (2000). Furthermore, for REE complexation with humic matter (i.e., humic and fulvic acids), we modified the default database of WHAM VII by replacing the average intrinsic equilibrium constants $\left(\mathrm{K}_{\mathrm{MA}}\right)$, with the corresponding values determined by Pourret et al. (2007).

We evaluated REE complexation with dissolved organic and inorganic ligands in the Mississippi River, and for comparison, the Amazon River, the world's largest river, which has been the focus of extensive studies of the REE (e.g., Rousseau et al., 2015 and references therein). The major ions concentrations used for REE complexation modeling (Table 2) in the Mississippi River water are those measured in this study, whereas both major ions,
TABLE 2 | Summary of input parameters used for the WHAM VII geochemical modeling.

\begin{tabular}{|c|c|c|c|c|c|}
\hline $\begin{array}{l}\text { Major } \\
\text { ions* }\end{array}$ & $\begin{array}{l}\text { Miss. River } \\
\text { mmol kg }^{-1}\end{array}$ & $\begin{array}{c}\text { Amazon River } \\
\text { mmol kg }\end{array}$ & REE* & $\begin{array}{l}\text { Miss. River } \\
\text { pmol kg }^{-1}\end{array}$ & $\begin{array}{c}\text { Amazon River } \\
\mathrm{pmol} \mathrm{kg}^{-1}\end{array}$ \\
\hline $\mathrm{HCO}_{3}$ & 0.94 & 0.28 & La & 150 & 763 \\
\hline $\mathrm{Na}$ & 0.44 & 0.07 & $\mathrm{Ce}$ & 239 & 1,556 \\
\hline $\mathrm{Mg}$ & 0.51 & 0.03 & $\operatorname{Pr}$ & 41 & 220 \\
\hline $\mathrm{Ca}$ & 0.40 & 0.09 & $\mathrm{Nd}$ & 184 & 943 \\
\hline K & 0.10 & 0.02 & $\mathrm{Sm}$ & 42 & 232 \\
\hline$F$ & 0.01 & - & Eu & 11 & 68 \\
\hline $\mathrm{Cl}$ & 0.65 & 0.03 & Gd & 52 & 226 \\
\hline $\mathrm{NO}_{3}$ & 0.03 & - & $\mathrm{Tb}$ & 7 & 27 \\
\hline \multirow[t]{2}{*}{$\mathrm{SO}_{4}$} & 0.41 & 0.02 & Dy & 41 & 205 \\
\hline & & & Ho & 9 & 39 \\
\hline $\mathrm{DOC}^{\mathrm{P}}$ & 0.29 & 0.42 & Er & 27 & 108 \\
\hline \multirow[t]{3}{*}{$\mathrm{pH}^{\star}$} & 7.80 & 6.89 & $\mathrm{Tm}$ & 4 & 20 \\
\hline & & & $\mathrm{Yb}$ & 24 & 92 \\
\hline & & & Lu & 4 & 13 \\
\hline
\end{tabular}

*Mississippi River data are from river water sample in this study, whereas Amazon River data are from Gaillardet et al. (1997).

PDissolved organic carbon (DOC) in $\mathrm{mmol} \mathrm{kg}^{-1}$, data from Thurman (1985).

and REE concentrations used for the Amazon River are from the "Amazon 20 after Santarem" location from Gaillardet et al. (1997). Dissolved organic carbon (DOC) concentrations used for modeling of the Mississippi and Amazon Rivers are $290 \mu \mathrm{mol}$ $\mathrm{kg}^{-1}$ and $417 \mu \mathrm{mol} \mathrm{kg}{ }^{-1}$ respectively, obtained from Thurman (1985). Following the approach of Tang and Johannesson (2010), we assumed that fulvic acid is the sole organic phase in the organic matter and that it constitutes $80 \%$ of the reported DOC concentrations.

\section{RESULTS}

\section{General Geochemistry and Major lons in the Mississippi River Water}

Field parameters that characterize the Mississippi River and estuary water samples are presented in Table 1, along with information detailing the specific sample locations (i.e., latitude and longitude), and collection depth. The $\mathrm{pH}$ of the waters range from 7.8 in the Mississippi River to 8.5 in the Louisiana Bight. Also, the salinities range from 0 in the Mississippi River to 36 in the Louisiana Bight. Major ions concentrations, including bicarbonate alkalinity of $0.94 \mathrm{mmol} \mathrm{kg} \mathrm{m}^{-1}$ measured in the Mississippi river water, as input for geochemical modeling are presented in Table 2, along with data for the Amazon River from Gaillardet et al. (1997).

\section{REE Concentrations of Mississippi River Estuary Waters}

The REE concentrations in the water samples are presented in Table 3, and the Post Archean Australian Shale (PAAS; McLennan, 1989) normalized REE fractionation patterns are shown in Figure 2. Shale-normalized REE patterns of Mississippi 
TABLE 3 | The REE concentrations, relative standard deviation (i.e., instrumental precision), and computed Ce and Gd anomalies of samples from the Mississippi River and Louisiana Shelf.

\begin{tabular}{|c|c|c|c|c|c|c|c|c|c|c|c|c|c|c|c|c|}
\hline \multirow[t]{2}{*}{ Sampling Point No. } & \multicolumn{15}{|c|}{ Concentrations $\left(\mathrm{pmol} \mathrm{kg}^{-1}\right) \pm \mathrm{RSD}$. } & \multirow[b]{2}{*}{$\mathbf{G d} / \mathbf{G d}^{\star}$} \\
\hline & La & $\mathrm{Ce}$ & $\operatorname{Pr}$ & Nd & Sm & Eu & Gd & Tb & Dy & Ho & Er & Tm & $\mathrm{Yb}$ & Lu & $\mathrm{Ce} / \mathrm{Ce}^{*}$ & \\
\hline \multirow[t]{2}{*}{ MR-channel } & 150 & 239 & 41 & 184 & 42 & 11 & 52 & 6.9 & 41 & 9.0 & 27 & 3.7 & 24 & 4.0 & 0.70 & 1.34 \\
\hline & 1.6 & 0.6 & 0.9 & 2.7 & 0.5 & 0.9 & 3.8 & 0.2 & 0.3 & 0.1 & 0.1 & 0.2 & 0.5 & 0.1 & & \\
\hline \multirow[t]{2}{*}{ MR-crevasse } & 133 & 210 & 37 & 168 & 38 & 10 & 46 & 6.4 & 39 & 8.5 & 25 & 3.5 & 23 & 3.8 & 0.69 & 1.28 \\
\hline & 1.5 & 0.9 & 0.4 & 1.7 & 0.9 & 1.6 & 4.2 & 0.1 & 0.5 & 0.0 & 0.2 & 0.1 & 0.1 & 0.1 & & \\
\hline \multirow[t]{2}{*}{0} & 78 & 70 & 25 & 97 & 21 & 5 & 35 & 6.6 & 52 & 7.2 & 25 & 3.2 & 22 & 3.2 & 0.36 & 1.07 \\
\hline & 2.4 & 0.7 & 1.1 & 6.6 & 0.3 & 0.7 & 3.5 & 0.7 & 2.1 & 0.7 & 1.2 & 0.1 & 0.8 & 0.1 & & \\
\hline \multirow[t]{2}{*}{2} & 98 & 80 & 23 & 104 & 23 & 7 & 33 & 5.0 & 35 & 8.3 & 26 & 3.7 & 22 & 3.5 & 0.39 & 1.24 \\
\hline & 2.4 & 0.1 & 0.2 & 2.9 & 0.7 & 2.5 & 1.1 & 0.2 & 2.1 & 0.1 & 0.8 & 0.1 & 1.3 & 0.1 & & \\
\hline \multirow[t]{2}{*}{3} & 102 & 80 & 22 & 95 & 21 & 5 & 29 & 4.6 & 32 & 7.7 & 24 & 3.5 & 19 & 3.3 & 0.39 & 1.20 \\
\hline & 0.9 & 2.3 & 0.7 & 1.2 & 0.9 & 1.8 & 0.9 & 0.2 & 0.6 & 0.2 & 0.3 & 0.1 & 0.1 & 0.2 & & \\
\hline \multirow[t]{2}{*}{4} & 95 & 71 & 22 & 104 & 23 & 7 & 34 & 5.1 & 37 & 9.0 & 28 & 4.1 & 23 & 3.9 & 0.36 & 1.26 \\
\hline & 1.1 & 0.4 & 0.1 & 4.5 & 0.7 & 0.8 & 1.1 & 0.1 & 0.5 & 0.1 & 0.9 & 0.1 & 0.3 & 0.2 & & \\
\hline \multirow[t]{2}{*}{5} & 155 & 141 & 31 & 138 & 30 & 8 & 41 & 6.0 & 46 & 10.7 & 35 & 5.1 & 30 & 4.9 & 0.47 & 1.27 \\
\hline & 2.8 & 0.5 & 0.4 & 1.5 & 1.2 & 3.0 & 0.4 & 0.1 & 1.9 & 0.4 & 1.4 & 0.1 & 0.4 & 0.1 & & \\
\hline \multirow[t]{2}{*}{$6 a$} & 94 & 32 & 15 & 71 & 15 & 5 & 23 & 4.2 & 34 & 7.6 & 25 & 3.4 & 21 & 3.3 & 0.19 & 1.10 \\
\hline & 0.9 & 0.4 & 0.2 & 1.3 & 0.3 & 1.9 & 0.7 & 0.1 & 1.5 & 0.1 & 0.6 & 0.1 & 0.9 & 0.1 & & \\
\hline \multirow[t]{2}{*}{$6 b$} & 75 & 52 & 15 & 68 & 15 & 6 & 21 & 3.2 & 26 & 5.7 & 19 & 2.8 & 16 & 2.5 & 0.35 & 1.21 \\
\hline & 1.1 & 0.8 & 0.2 & 2.7 & 0.7 & 0.8 & 0.7 & 0.1 & 0.6 & 0.2 & 0.8 & 0.1 & 0.7 & 0.2 & & \\
\hline \multirow[t]{2}{*}{$6 c$} & 85 & 58 & 19 & 90 & 23 & 6 & 31 & 4.7 & 36 & 8.3 & 28 & 4.0 & 25 & 4.0 & 0.33 & 1.20 \\
\hline & 1.1 & 0.1 & 0.3 & 1.2 & 1.3 & 2.7 & 1.0 & 0.1 & 0.6 & 0.2 & 1.1 & 0.1 & 0.4 & 0.1 & & \\
\hline \multirow[t]{2}{*}{8} & 77 & 42 & 17 & 83 & 20 & 5 & 29 & 4.1 & 34 & 7.6 & 25 & 3.6 & 21 & 3.5 & 0.27 & 1.32 \\
\hline & 0.6 & 0.6 & 0.3 & 1.8 & 0.3 & 0.9 & 0.9 & 0.1 & 1.7 & 0.1 & 0.3 & 0.1 & 0.9 & 0.1 & & \\
\hline \multirow[t]{2}{*}{9} & 87 & 69 & 19 & 88 & 22 & 6 & 32 & 4.6 & 35 & 8.2 & 26 & 3.6 & 22 & 3.6 & 0.39 & 1.29 \\
\hline & 1.0 & 0.8 & 0.5 & 1.8 & 0.6 & 2.6 & 1.6 & 0.1 & 1.4 & 0.2 & 0.9 & 0.2 & 0.8 & 0.1 & & \\
\hline \multirow[t]{2}{*}{$10 \mathrm{a}$} & 65 & 28 & 11 & 51 & 12 & 4 & 18 & 3.0 & 26 & 5.9 & 20 & 2.8 & 18 & 2.8 & 0.24 & 1.15 \\
\hline & 1.0 & 0.1 & 0.2 & 2.4 & 0.8 & 1.1 & 1.0 & 0.1 & 0.6 & 0.1 & 0.4 & 0.1 & 0.6 & 0.1 & & \\
\hline \multirow[t]{2}{*}{$10 b$} & 62 & 37 & 14 & 59 & 12 & 4 & 20 & 3.0 & 28 & 5.7 & 20 & 2.9 & 16 & 2.5 & 0.30 & 1.26 \\
\hline & 0.2 & 0.5 & 0.2 & 2.3 & 0.8 & 1.6 & 0.4 & 0.1 & 0.3 & 0.2 & 0.4 & 0.1 & 0.3 & 0.1 & & \\
\hline \multirow[t]{2}{*}{$10 c$} & 58 & 42 & 15 & 66 & 15 & 5 & 24 & 3.9 & 33 & 6.8 & 24 & 3.5 & 20 & 3.4 & 0.33 & 1.23 \\
\hline & 1.0 & 1.0 & 0.3 & 1.9 & 1.6 & 1.8 & 0.6 & 0.2 & 0.6 & 0.3 & 0.9 & 0.1 & 0.8 & 0.1 & & \\
\hline
\end{tabular}

Anomalies: $\mathrm{Ce} / \mathrm{Ce}^{*}=2[\mathrm{Ce}] n /([\mathrm{La}] \mathrm{n}+[\mathrm{Pr}] \mathrm{n}) ; \mathrm{Gd} / \mathrm{G} d^{*}=[\mathrm{Gd}] \mathrm{n} /(0.33[\mathrm{Sm}] n+0.67[\mathrm{~Tb}] \mathrm{n})$, where $n$ refers to shale-normalized values.

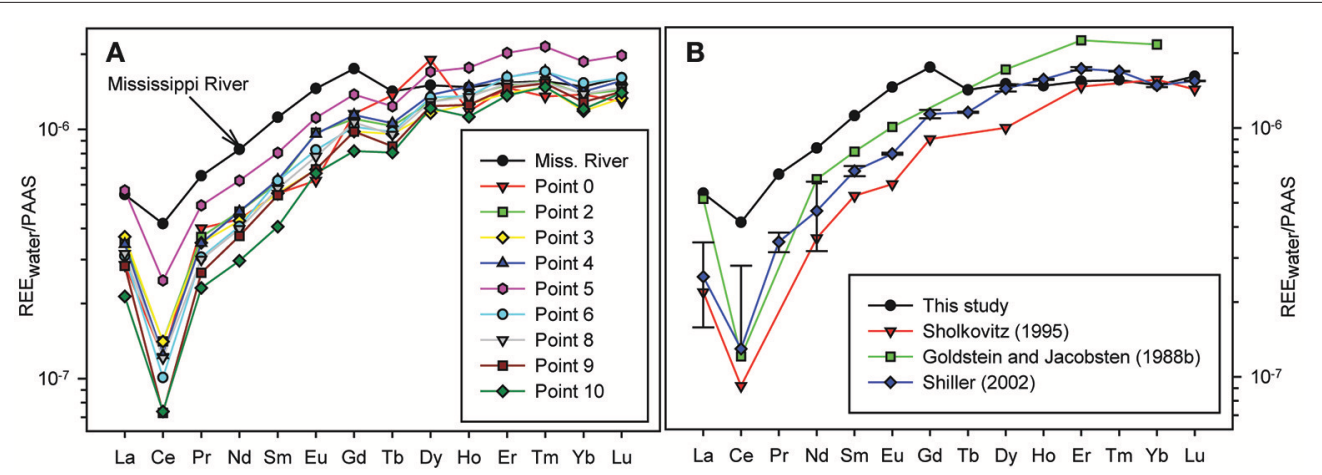

FIGURE 2 | (A) PAAS-normalized REE patterns for water samples collected from the Mississippi River and Louisiana Bight. (B) A comparison of Mississippi River water sample (salinity $\approx 0$ ) from this study with previous studies. The data from Shiller (2002) are discharge-weighted mean values. 
River and estuarine waters are heavy REE (HREE) enriched (Figure 2A), which is consistent with results from previous studies (Goldstein and Jacobsen, 1988a,b; Sholkovitz, 1995; Shiller, 2002; Figure 2B). Light REE (LREE) concentrations reported here for the Mississippi River are higher than many of the previous analyses, whereas the HREE concentrations fall within the same range. For example, we measured a $\mathrm{Nd}$ concentration of $184 \mathrm{pmol} \mathrm{kg}^{-1}$ (sample MR in Table 3), which is 2.3 times higher than the $\mathrm{Nd}$ concentration $\left(80 \mathrm{pmol} \mathrm{kg}^{-1}\right.$ ) reported by Sholkovitz (1995), 1.8-fold higher than the dischargeweighted mean (103 pmol kg-1) of Shiller (2002), and a factor of 1.4 higher than the value of $138 \mathrm{pmol} \mathrm{kg}^{-1}$ reported by Goldstein and Jacobsen (1988b). However, our La value (150 pmol kg-1) compares well with the value (142 $\mathrm{pmol} \mathrm{kg}^{-1}$ ) reported by Goldstein and Jacobsen (1988b). In contrast, our measured Yb concentration of $24 \mathrm{pmol} \mathrm{kg}^{-1}$ is identical to those determined by Sholkovitz (1995) and Shiller (2002), who reported 25.3 pmol kg-1 and $24 \mathrm{pmol} \mathrm{kg}^{-1}$ respectively, and lower than the $\mathrm{Yb}$ concentration of $35 \mathrm{pmol} \mathrm{kg}^{-1}$ reported by Goldstein and Jacobsen (1988b).
All the Mississippi River estuary samples show negative Ce anomalies, with the more saline waters of the Louisiana Bight commonly exhibiting more pronounced negative Ce anomalies compared to the fresh river water (Table 3; Figure 2). Specifically, the river water has a Ce anomaly of 0.7 , whereas the mean $\pm 1 \sigma$ of waters from the Louisiana Bight is $0.34 \pm 0.07$. The estuarine samples also have small, positive Gd anomalies, which initially decrease from $\sim 1.32$ in the fresh river water to $\sim 1.05$ in the low salinity sample $(S=8)$, before increasing to values between $\sim 1.2$ and 1.3 within the Louisiana Bight. The mean $\pm 1 \sigma$ of Gd anomalies for waters from the Louisiana Bight is $1.22 \pm 0.07$.

Concentrations of selected LREE, middle REE (MREE), and HREE are shown in Figures 3A-C as a function of salinity within the Mississippi River estuary. The LREE show a pronounced decrease in concentration with increasing salinity in the Mississippi River estuary, which is not obvious for MREE or HREE. For example, the Nd concentration of the surface waters decrease from $184 \mathrm{pmol} \mathrm{kg}^{-1}$ in the fresh river water (sample $\mathrm{MR}$ ) to $65.8 \mathrm{pmol} \mathrm{kg}^{-1}$ in the most saline water sample collected from the Louisiana Bight (sample 10c, $S=27.5$; Figure 3A). In

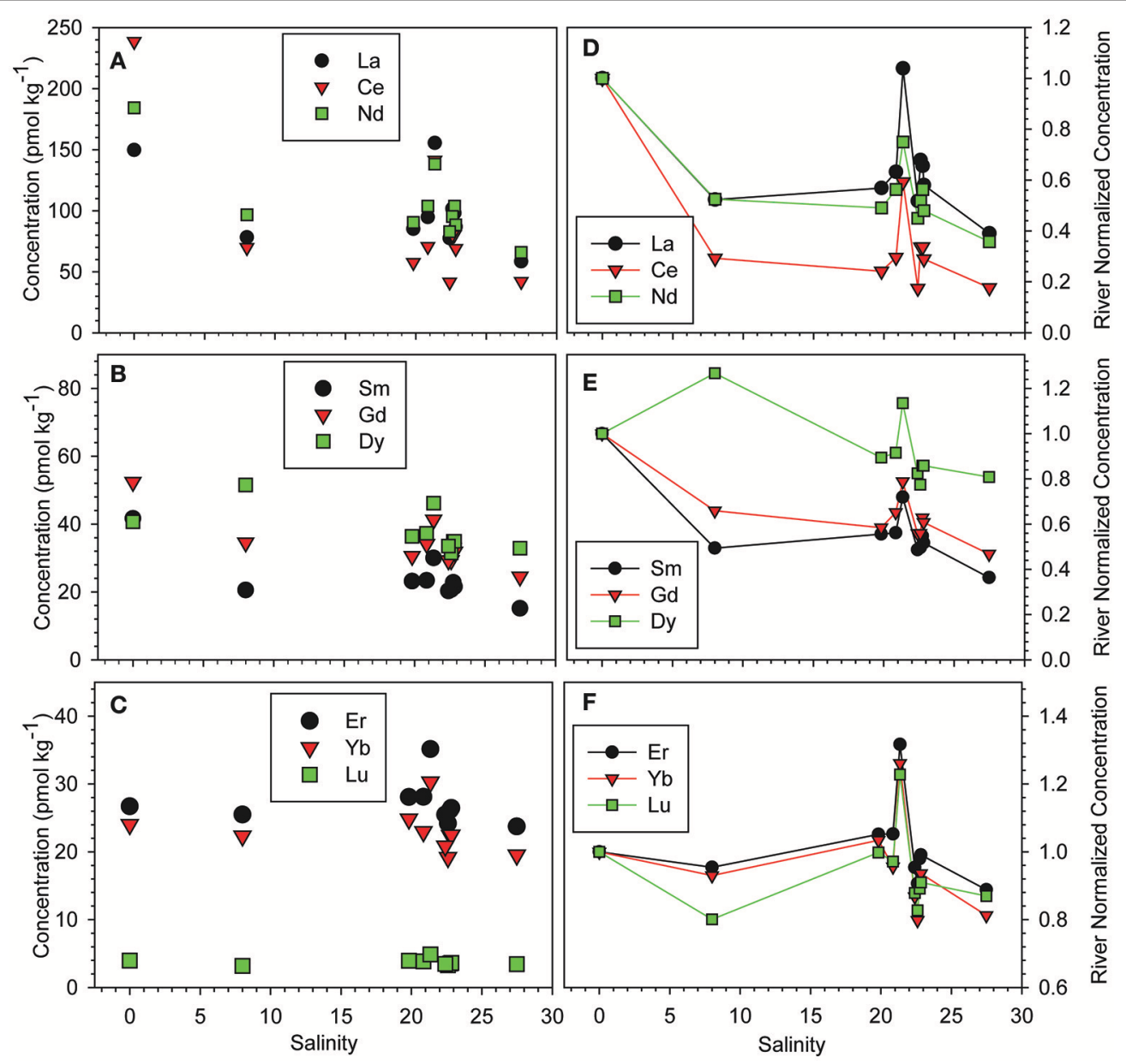

FIGURE 3 | Concentrations of selected (A) LREE (La, Ce, Nd), (B) MREE (Sm, Gd, Dy), and (C) HREE (Er, Yb, Lu) as a function of salinity in the Mississippi River estuary. (D-F) River normalized concentrations of the same selected LREE, MREE, and HREE as a function of salinity in the Mississippi River estuary. 
contrast, the Lu concentration decreases from $3.96 \mathrm{pmol} \mathrm{kg}^{-1}$ to $3.45 \mathrm{pmol} \mathrm{kg}^{-1}$ for these same samples (Figure 3C). A notable feature of the Mississippi River estuary is the "spike" in REE concentrations in the mid to high salinity region (i.e., $20 \leq S$ $\leq 25$ ), which affects all the REE (Figure 3). For example, $\mathrm{Nd}$ increases from 90.4 to $138.2 \mathrm{pmol} \mathrm{kg}^{-1}$ between salinities 19.8 and 21.3 , before decreasing to $103.8 \mathrm{pmol} \mathrm{kg}^{-1}$ at salinity 22.7 . The data indicate that $\mathrm{Tm}$ concentrations in this region of the estuary are as much as $40 \%$ greater than in the Mississippi River, and Dy values are roughly 27\% higher (Figure 3E).

Rare earth elements concentrations of the estuary waters are normalized to the fresh river water sample, and plotted as a function of salinity in Figures 3D-F. These plots reveal that within the low salinity region of the estuary (i.e., $S \leq 8$ ), the river water-normalized REE concentrations decrease by as much as $71 \%$ for Ce and $48 \%$ for Nd (Figure 3D), and as little as 5 and 7\% for $\mathrm{Er}$ and $\mathrm{Yb}$, respectively (Figure 3F). River water-normalized $\mathrm{Nd}$ concentrations for the Mississippi River estuary are compared in Figure 4, to data for the majority of other estuaries studied to date. The outstanding feature of these data is that $\mathrm{Nd}$ removal in the Mississippi River estuary is substantially less than observed in these other estuaries. For example, Nd only decreases by ca. $50 \%$ in the Mississippi River estuary, compared to ca. $90 \%$ in the Amazon River estuary over the same salinity range. The most saline surface water sample from the Mississippi River estuary has a $\mathrm{Nd}$ concentration that is ca. $38 \%$ of the river water endmember, which translates to an overall removal of $62 \%$ for river sourced $\mathrm{Nd}$ across the estuary.

\section{Complexation Model Results}

Results of the solution complexation modeling are presented in Figure 5 for the Mississippi River and Amazon River for comparison. In the Mississippi River water, the model predicts that $>95 \%$ of each REE occurs complexed with humic matter (Figure 5A). For the inorganic complexes, the model predicts e.g., Carbonato complexes, $\mathrm{LnCO}_{3}^{+}$, to account for at most $\sim 1 \%$ of $\mathrm{Ce}$ in solution, with the dicarbonato complexes, $\operatorname{Ln}\left(\mathrm{CO}_{3}\right)_{2}^{-}$, accounting for at most $0.1 \%$ of $\mathrm{Ce}$ (Figure 5A). Speciation modeling predictions for the Amazon River are similar to those for the Mississippi River, with $>90 \%$ of each REE predicted as organic matter complexes (Figure 5B). However, the model predicts that greater amounts of the LREE will occur in Amazon River waters as carbonato complexes (e.g., 6-7\% for Ce) and as free metal ions (e.g., $\sim 1 \%$ for La; compare Figures $5 \mathbf{A}, \mathbf{B}$ ). The predicted dominance of organic REE complexes in both the Mississippi and Amazon Rivers is consistent with previous studies, that REE are carried in most major world rivers as organic matter complexes (e.g., Tang and Johannesson, 2003; Pourret et al., 2007).

\section{REE Content of Mississippi River Sediment} The REE content of the operationally defined fractions of the Mississippi River bank sediment are presented in Table 4. Percentage distribution of the REE in each fraction, and the shale-normalized REE patterns are shown in Figure 6. The REE concentrations increase with successive leaching as follows: exchangeable $<$ acid leachable $<$ reducible $<$ oxidizable $<$ residual. The total bulk sediment, sum of all five sequential extractions, and the residual fraction of the sediment have flat shale-normalized patterns. The oxidizable, reducible and acid leachable fractions have MREE enriched shale-normalized patterns, whereas the readily exchangeable fraction is depleted in the LREE. The differences in shale-normalized REE patterns of the various leached fractions are also reflected in their Sm/Nd ratios. For example, the highest $\mathrm{Sm} / \mathrm{Nd}$ ratio $(0.58)$ is observed for the exchangeable fraction, which is strongly depleted in the LREE, whereas the residual fraction has the lowest $\mathrm{Sm} / \mathrm{Nd}$ ratio (0.18). The computed MREE enrichments (i.e., MREE/MREE*; Haley et al., 2004) range from a low of 1.06 for the residual silicates, to a high of 2.05 for the acid leachable.

\section{Mississippi River Water and SPM $\varepsilon_{\mathrm{Nd}(0)}$}

Neodymium isotope values [i.e., $\varepsilon_{\mathrm{Nd}(0)}$ ] for Mississippi River water samples, and the labile fraction of the associated SPM analyzed in this study are presented in Table 5. In addition, all known Nd isotope data for the Mississippi River system from the literature are reproduced in Table 5. These data include variously filtered river waters and associated SPM from different locations along the river, as well as sediment samples. The $\mathrm{Nd}$ isotope composition of the two Mississippi River waters sampled are identical, within analytical error (i.e., $2 \sigma$ ), exhibiting $\varepsilon_{\mathrm{Nd}(0)}$ values of -10.5 (Table 5). In contrast, $\varepsilon_{\mathrm{Nd}(0)}$ values for the acid leachable fraction of SPM from the MR site in the lower Mississippi River are more radiogenic than the river water from the same location [i.e., mean $\varepsilon_{\mathrm{Nd}(0)}$ ca. -9.9 ; Table 5].

\section{DISCUSSION}

\section{Controls on REE in the Mississippi River Estuary}

The REE concentrations measured in the Mississippi River water in this study are in general agreement with previous studies, and the difference in LREE concentrations shown in Figure 2B likely reflects seasonal variations. For example, Shiller (2002) reported a $\mathrm{Nd}$ concentration of $163 \mathrm{pmol} \mathrm{kg}^{-1}$ in January 1992, which is higher than his discharge-weighted mean $\mathrm{Nd}$ concentration, and closer to the $\mathrm{Nd}$ concentration (184 pmol $\mathrm{kg}^{-1}$ ) we measured in this study, which was also sampled in January. Shiller (2002) noted that seasonal variability is more pronounced for the LREE relative to the HREE in Mississippi River water, with the LREE exhibiting a 5-fold variation between winter and summer. Another possible factor that could explain our higher LREE concentrations may be related to sampling locations. All previous samplings of the Mississippi River were upstream of Baton Rouge, Louisiana, whereas we sampled the river near its mouth (Figure 1).

Shale-normalized REE patterns in this study show both Ce and Gd anomalies in all the water samples (Table 3; Figure 2A). The observed negative Ce anomaly becomes greater as the "fresh" water from the Mississippi River (Ce anomaly $=0.7$ ) mixes with the more saline water in the Louisiana Bight (mean $\pm 1 \sigma ; 0.34$ \pm 0.07 ). These negative $\mathrm{Ce}$ anomalies are attributable to the higher particle reactivity of Ce owing to its redox sensitivity, relative to its neighboring REE. This higher particle reactivity of 

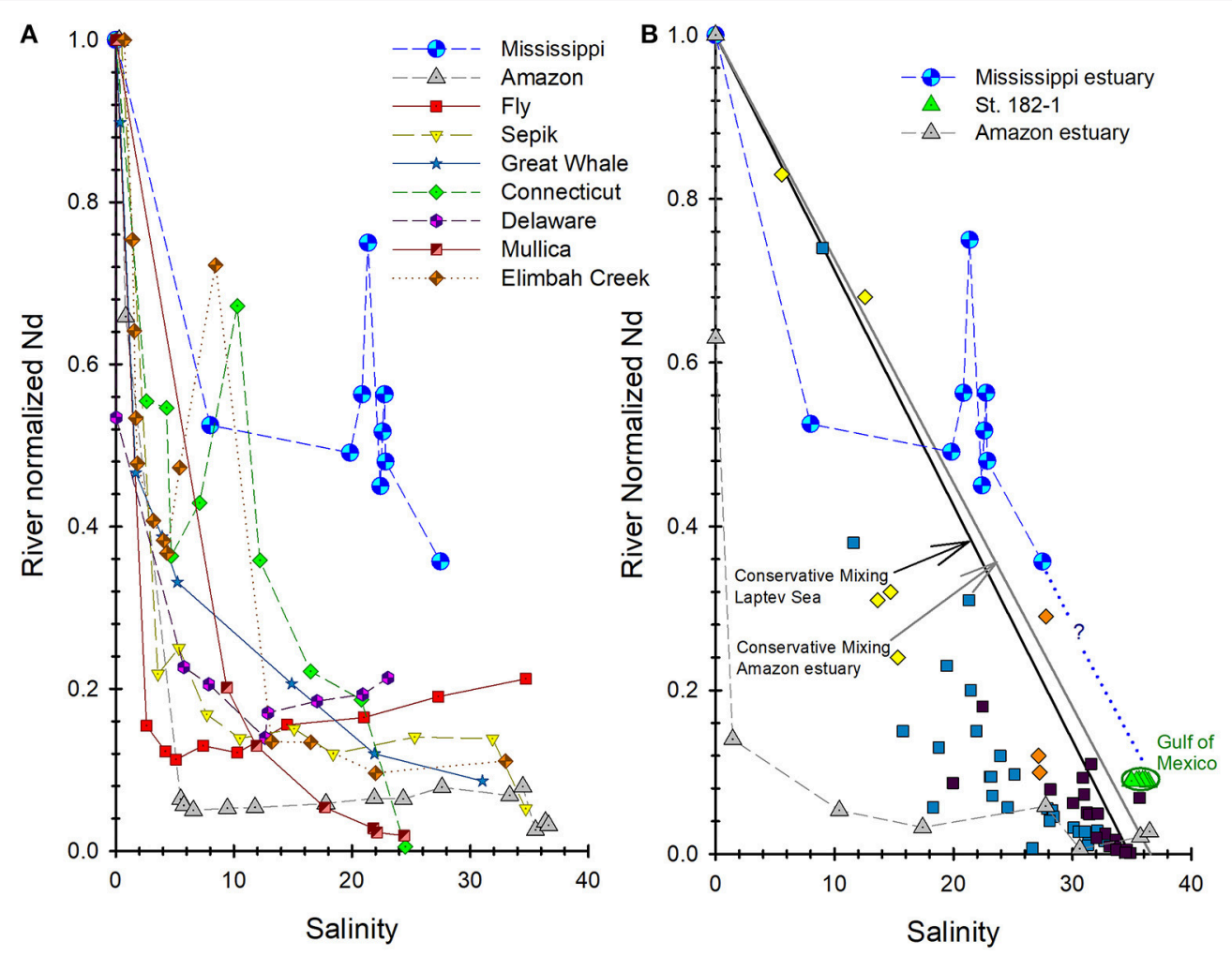

FIGURE 4 | River water-normalized Nd concentrations through the Mississippi River (MR) estuary (locations from Figure 1; this study) compared to other river/estuarine systems. (A) Compares the MR estuary to estuarine systems reviewed in Rousseau et al. (2015). (B) Compares the MR estuary's "conservative mixing" with station 182-1 in Osborne et al. (2015) to river/estuarine systems of the Laptev Sea (Figure 8a in Laukert et al., 2017), and the Amazon River estuary (Rousseau et al., 2015).

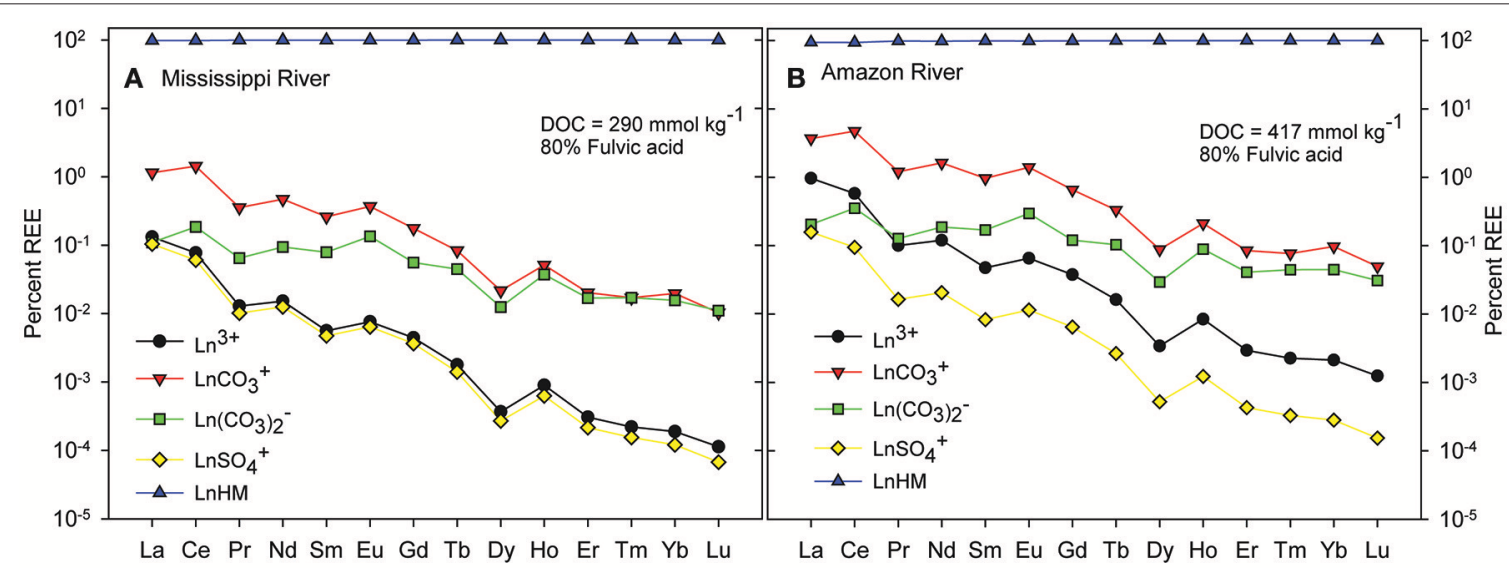

FIGURE 5 | Solution complexation modeling (WHAM VII) results for (A) the Mississippi River water, and (B) the Amazon River water, where Ln represents individual REE, and HM represents humic material. Note that the ordinate scales are logarithmic.

Ce becomes amplified during salt induced coagulation of colloids in the estuary, which is responsible for the increase in the negative Ce anomaly with increasing salinity (Elderfield et al., 1990; Sholkovitz, 1995; Shiller, 2002). For Gd anomalies, we recognize that anthropogenic Gd from the use of gadopentetic acid in magnetic resonance imaging may contribute to the positive Gd anomalies observed in Mississippi River water (1.34) and waters from the Louisiana Bight (mean $\pm 1 \sigma ; 1.22 \pm 0.07$ ). In which case we assume that dilution effect due to the size of the Mississippi River results in the small magnitude of these values. On the other hand, the positive Gd anomalies found in all the water samples in this study are within the range typical of unpolluted 
TABLE 4 | The REE concentrations of the sequentially extracted operationally defined fractions of Mississippi River sediment, and computed Sm/Nd ratios and MREE enrichment.

\begin{tabular}{|c|c|c|c|c|c|c|c|c|c|c|c|}
\hline \multicolumn{12}{|c|}{ - Fractions - } \\
\hline & Exchangeable - F1 & & Acid leachable - F2 & & Reducible - F3 & & Oxidizable - F4 & & Residual - F5 & Sum of & Total digestion \\
\hline & $\mu \mathrm{g} \mathrm{kg}^{-1}$ & \pm & $\mu \mathbf{g ~ k g}^{-1}$ & \pm & $\mu \mathrm{g} \mathrm{kg}^{-1}$ & \pm & $\mu \mathbf{g ~ k g}^{-1}$ & \pm & $\mu \mathrm{g} \mathrm{kg}^{-1}$ & $\mu \mathbf{g ~ k g}^{-1}$ & $\mu \mathbf{g ~ k g}^{-1}$ \\
\hline $\mathrm{La}$ & 9 & 1 & 567 & 45 & 2,697 & 211 & 5,285 & 124 & 16,928 & 25,486 & 35,503 \\
\hline $\mathrm{Ce}$ & 37 & 4 & 1,192 & 121 & 6,997 & 804 & 12,120 & 193 & 32,660 & 53,007 & 68,785 \\
\hline $\operatorname{Pr}$ & 6 & 1 & 182 & 13 & 895 & 78 & 1,462 & 53 & 3,945 & 6,491 & 8,358 \\
\hline $\mathrm{Nd}$ & 47 & 6 & 898 & 62 & 3,824 & 279 & 5,612 & 181 & 13,895 & 24,276 & 30,810 \\
\hline Sm & 27 & 1 & 259 & 20 & 949 & 40 & 1,256 & 51 & 2,525 & 5,017 & 6,133 \\
\hline Eu & 13 & 1 & 81 & 3 & 255 & 11 & 305 & 5 & 608 & 1,262 & 1,403 \\
\hline $\mathrm{Gd}$ & 27 & 2 & 333 & 26 & 1,097 & 71 & 1,512 & 39 & 2,567 & 5,536 & 6,472 \\
\hline $\mathrm{Tb}$ & nd & - & 33 & 3 & 127 & 8 & 189 & 13 & 277 & 626 & 750 \\
\hline Dy & 23 & 2 & 227 & 17 & 778 & 61 & 1,123 & 48 & 1,647 & 3,797 & 4,400 \\
\hline Ho & 7 & 0 & 49 & 4 & 157 & 7 & 226 & 8 & 354 & 792 & 907 \\
\hline Er & 24 & 2 & 124 & 6 & 425 & 26 & 603 & 13 & 1,070 & 2,247 & 2,664 \\
\hline Tm & nd & - & 13 & 0 & 52 & 3 & 77 & 4 & 157 & 299 & 382 \\
\hline $\mathrm{Yb}$ & 24 & 2 & 90 & 6 & 344 & 23 & 479 & 3 & 1,121 & 2,058 & 2,637 \\
\hline Lu & 3 & 0 & 14 & 0 & 50 & 5 & 67 & 2 & 176 & 309 & 393 \\
\hline $\mathrm{Sm} / \mathrm{Nd}$ & 0.58 & & 0.29 & & 0.25 & & 0.22 & & 0.18 & 0.21 & 0.20 \\
\hline $147 \mathrm{Sm} / 144 \mathrm{Nd}$ & 0.35 & & 0.18 & & 0.15 & & 0.13 & & 0.11 & 0.13 & 0.12 \\
\hline MREE/MREE ${ }^{\star}$ & 1.56 & & 2.05 & & 1.69 & & 1.52 & & 1.06 & & 1.19 \\
\hline
\end{tabular}

nd, below detection limit. *MREE enrichments (Haley et al., 2004).

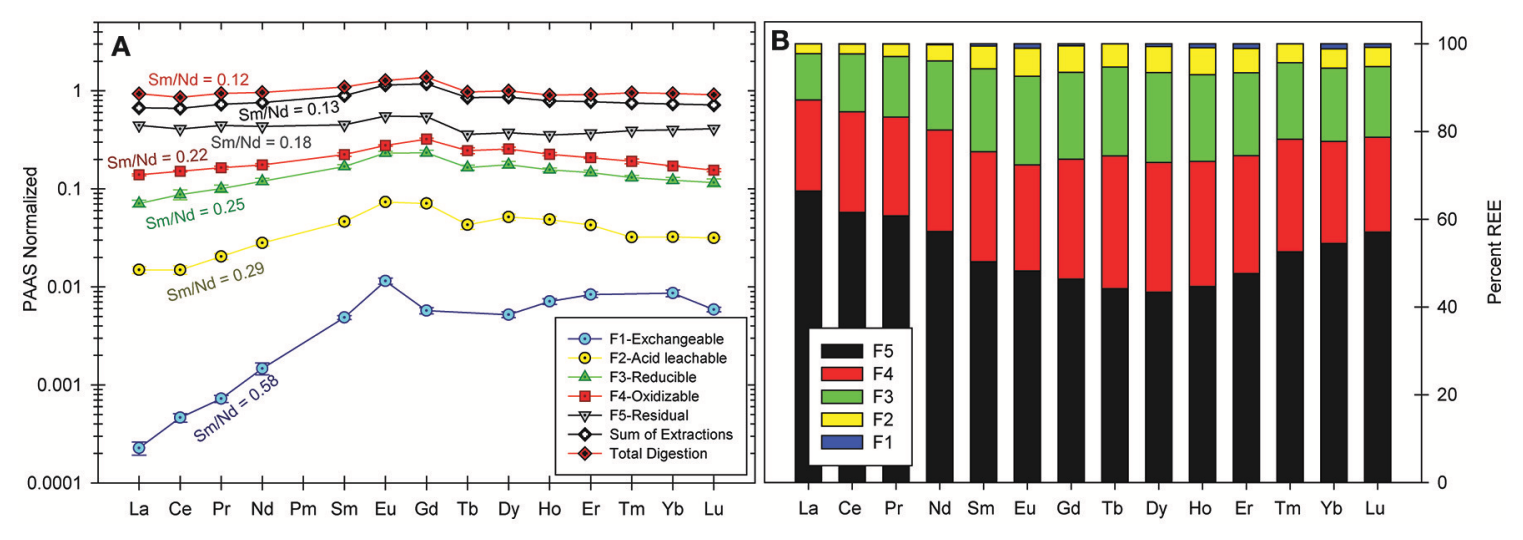

FIGURE 6 | (A) PAAS-normalized REE patterns of different operationally defined fractions from sequential extractions of Mississippi River sediment, and comparison of the sum of extractions to a single total digestion of sample aliquot. (B) Percentage distribution of the REE between the operationally defined fractions.

natural waters, including seawater, and much less than the values $(\geq 4)$ reported for most waters affected by anthropogenic Gd input (e.g., Kim et al., 1991; Bau and Dulski, 1996). Hence, the positive Gd anomalies observed here may be analogous to naturally occurring positive Gd anomalies, which are attributed to ionic radius independent fractionation due to Gd's half-filled 4-f electron shell, which affects both the solution and surface complexation behavior of Gd compared to Eu and $\mathrm{Tb}$ (Kim et al., 1991; Bau and Dulski, 2003).

Two observations have been extensively reported regarding REE concentrations in estuaries: removal in the low salinity region and release in the mid to high salinity region. For example, such behavior has been described for the estuary of the world's largest river, the Amazon River (e.g., Rousseau et al., 2015 and references therein). Rare earth elements concentrations also decrease as Mississippi River water first mixes with Gulf of Mexico water on the Louisiana Shelf (Figure 3). These observations are consistent with change in water chemistry (e.g., ionic strength) with increase in salinity, which nullifies the repulsive energy barrier between colloidal particles, bringing about flocculation and settling out of colloids (Edzwald et al., 1974). In this study, the removal by this mechanism follows the 
TABLE 5 | Neodymium concentrations and isotopic compositions, $\varepsilon_{\mathrm{Nd}(0)}$ values, of Mississippi River water, suspended particulate matter (SPM), and sediment.

\begin{tabular}{|c|c|c|c|c|}
\hline Sample type & Filter $(\mu \mathrm{m})$ & Nd & $\varepsilon \mathrm{Nd}(0)$ & Location \\
\hline Water $^{\mathrm{a}}$ & 0.1 & $32.6 \mathrm{pmol} \mathrm{kg}-1$ & $-12.1 \pm 0.5$ & Pilotstown, LA \\
\hline Water $^{\mathrm{b}}$ & 0.2 & 318 pmol kg ${ }^{-1}$ & -19.5 & Jackson, MN \\
\hline Water $^{\mathrm{b}}$ & 0.2 & 165 pmol kg ${ }^{-1}$ & -8.6 & Chester, IL \\
\hline Water $^{\mathrm{a}}$ & 0.4 & $81.1 \mathrm{pmol} \mathrm{kg}^{-1}$ & $-10.5 \pm 0.5$ & Pilotstown, LA \\
\hline Water $^{\mathrm{a}}$ & 0.4 & $76.3 \mathrm{pmol} \mathrm{kg}^{-1}$ & $-12.1 \pm 0.5$ & Venice, LA \\
\hline $\begin{array}{l}\text { Water }{ }^{\mathrm{C}} \text { (River } \\
\text { channel) }\end{array}$ & 0.45 & 184 pmol kg-1 & $-10.55 \pm 0.29$ & Near Venice, LA \\
\hline $\begin{array}{l}\text { Water-2c (Breton } \\
\text { Sound) }\end{array}$ & 0.45 & 168 pmol kg-1 & $-10.53 \pm 0.33$ & Near Venice, LA \\
\hline SPM $^{d}$ & $>0.2$ & 30.4 ppm & -19.4 & Jackson, MN \\
\hline SPM $^{d}$ & $>0.2$ & 40.8 ppm & -10.1 & Chester, IL \\
\hline $\begin{array}{l}\text { SPM }^{\mathrm{C}} \text { (Acid } \\
\text { leachable) }\end{array}$ & 0.45 & 0.12 ppm & $-9.95 \pm 0.20$ & Near Venice, LA \\
\hline $\begin{array}{l}\text { SPM-2C (Acid } \\
\text { leachable) }\end{array}$ & 0.45 & 0.15 ppm & $-9.77 \pm 0.23$ & Near Venice, LA \\
\hline Sediment $^{\mathrm{e}}$ & & 32.6 ppm & -10.9 & Near Venice, LA \\
\hline Sediment $^{\dagger}$ (clays) & & 39.8 ppm & -10.8 & Delta front \\
\hline Sediment ${ }^{\dagger}$ (silts) & & 30.3 ppm & -12.3 & Delta front \\
\hline
\end{tabular}

a Stordal and Wasserburg (1986); 'b Goldstein and Jacobsen (1987); ' This study (location MR in Figure 1); ${ }^{d}$ Goldstein and Jacobsen (1988a); ${ }^{e}$ Goldstein et al. (1984); ${ }^{f}$ Bayon et al. (2015).

general order LREE > MREE > HREE (Figure 3), likely because of the higher particle reactivity of the LREE. Also because the HREE, and to a lesser extent, the MREE, form stronger solution complexes than the LREE (Sholkovitz, 1995; Nozaki et al., 2000; Sholkovitz and Szymczak, 2000).

The global average removal of $\mathrm{Nd}$ in estuaries has been estimated to be roughly $70 \%$ of the river borne $\mathrm{Nd}$ concentration (Goldstein and Jacobsen, 1987), although many estuaries exhibit greater amounts of $\mathrm{Nd}$ removal (e.g., $>90 \%$ for the Amazon; Figure 4A). Many, but not all estuaries also exhibit release of REE back to the water column at mid to high salinities (Figure 4A). Others, including the Connecticut River estuary, the Chao Phraya River estuary (Thailand), and Elimbah Creek (Australia) exhibit concentration "spikes" over relatively narrow salinity ranges at various salinities (Figure 4A). These concentration "spikes," such as observed on the Louisiana Shelf are commonly attributed to sediment resuspension, remineralization of estuary sediments, and/or desorption of REE from SPM (Nozaki et al., 2000; Lawrence and Kamber, 2006).

An outstanding feature of the Mississippi River estuary is what appears to be lower amounts of REE removal in the low salinity region of the estuary when compared to the majority of other estuaries investigated (Figures 3, 4). For example, 97\% of the $\mathrm{Nd}$ in the Amazon River is estimated to be removed in the low salinity region of its estuary, compared to only ca. $50 \%$ in the Mississippi River estuary (Figure 4). More specifically, our data suggest that slightly more than $62 \%$ of the river borne $\mathrm{Nd}$ in the Mississippi River is removed from solution by salinity ca. 30 compared to between 94 and 99\% removal of river borne $\mathrm{Nd}$ in the Amazon River estuary at the same salinity (Figure 4). This relative stability of REE in the Mississippi River estuary compared to most other estuaries is intriguing and requires explanation.

There are a number of possibilities that could explain this apparent stability of the REE in the Mississippi River estuary. First, the high $\mathrm{pH}$ of the Mississippi River water $(\sim 8.0)$ may in part be responsible for the relatively lower REE removal during estuarine mixing compared to other estuaries, such as the Amazon estuary, which has a lower pH of 6.9 (Rousseau et al., 2015). The higher $\mathrm{pH}$ of the Mississippi River water translates to lower REE concentrations compared to the Amazon River. For example, we measured a $\mathrm{Nd}$ concentration of $184 \mathrm{pmol}$ $\mathrm{kg}^{-1}$ in the Mississippi River, whereas a $\mathrm{Nd}$ concentration of $942 \mathrm{pmol} \mathrm{kg}^{-1}$ was reported for the Amazon River (Amazon 20) by Gaillardet et al. (1997), and Rousseau et al. (2015) reported a $\mathrm{Nd}$ concentration of $852 \mathrm{pmol} \mathrm{kg}^{-1}$. Lower amounts of REE available for removal during flocculation follows similar argument advanced to explain the relatively low Fe removal in the Mississippi River estuary (Shiller and Boyle, 1991). In addition, the high $\mathrm{pH}$ of Mississippi River water suggests that greater proportions of each REE will occur in solution as stable aqueous complexes with organic ligands and carbonate ions (Figure 5). A previous study of the Mississippi River estuary also attributed low Fe removal, in part, to formation of strong aqueous complexes with dissolved natural organic ligands (Powell and Wilson-Finelli, 2003).

Although broadly similar, the aqueous complexation model predicts that REE complexes with natural organic matter account for more of each REE in Mississippi River water compared to the Amazon River (Figure 5), despite the latter having higher DOC concentration (i.e., $417 \mu \mathrm{mol} \mathrm{kg}{ }^{-1}$ compared to $290 \mu \mathrm{mol} \mathrm{kg}-1$ in the Mississippi River; Thurman, 1985). Specifically, the model predicts that $99.4 \%$ of $\mathrm{Nd}$ in the Mississippi River, compared to 97.9\% of $\mathrm{Nd}$ in the Amazon River is complexed with natural organic matter. Conversely, $0.02 \%$ free $\mathrm{Nd}$ ions $\left[\mathrm{Nd}^{3+}\right]$ is in solution in the Mississippi River, compared to approximately an order of magnitude greater, $0.12 \%$ as $\mathrm{Nd}^{3+}$ in the Amazon River. Because the free metal ion species, $\mathrm{Ln}^{3+}$, is the most chemically reactive form of the REE in solution, the higher proportion of $\mathrm{Ln}^{3+}$ in the Amazon River indicates that it has relatively more REE available for binding onto the surface of colloids than the Mississippi River. These arguments are consistent with recent field and experimental studies of estuaries, where it was shown that river waters dominated by organic nanoparticles and colloids (NPCs) exhibited markedly less removal of REE from solution when mixed with seawater compared to rivers with predominantly inorganic NPCs (Tepe and Bau, 2016; Merschel et al., 2017). These studies employed various filtration techniques including ultrafiltration to investigate colloidal and "truly" dissolved fractions of the REE, and the organic matter phase in WHAM VII is defined as colloidal (Tipping et al., 2011).

Another possible explanation for the apparent stability of the REE across the salinity gradient in the Mississippi River estuary is that REE contributions from sediment sources on the Louisiana Shelf mask the true amount of estuarine removal. Shallow estuaries associated with large rivers discharging along coasts with extensive continental shelf regions exhibit pronounced release of REE from the shelf sediments, owing to intense 
sediment-water interactions (Sholkovitz and Szymczak, 2000). Processes such as disaggregation, desorption, mineralization, and bioturbation may influence the REE content of both particulate and dissolved phases in shallow estuaries (McKee et al., 2004; Abbott et al., 2015). The Louisiana Bight is such a setting, with an average depth of $\sim 20 \mathrm{~m}$, possibly explaining the "spike" in REE concentrations in the MRP for salinities between 20 and 25 (Figure 3). Also, a conservative mixing line appears to be generated (Figure 4B), by plotting the river water-normalized REE concentrations of the Mississippi River estuary waters from this study with seawater samples from station 182-1 (Osborne et al., 2015) located approximately $130 \mathrm{~km}$ due east of the birdfoot delta, see Figure 8. This observation parallels conservative mixing lines for the Amazon River estuary and estuaries from the Laptev Sea (Figure 4B). This parallel relationship further suggests that dissolution of labile mineral phases from sediment resuspension impacts the distribution of the REE in the estuary. Nonetheless, it is not known whether the observed REE concentrations "spikes" are a common feature of the Mississippi River estuary or are spatially and/or temporally limited.

Dissolution of the labile mineral phases of river sourced sediments in coastal regions is recognized as an important flux of trace elements to the ocean (e.g., Pearce et al., 2013; Jeandel and Oelkers, 2015). Because of the substantial sediment load of the Mississippi River, which covers large regions of the Gulf of Mexico, the river sediments likely exert important controls on REE concentrations and $\mathrm{Nd}$ isotope composition of the Gulf (Trefry and Shokes, 1981; Figure 8). A previous study demonstrated that Mississippi River sediments play an important role in the $\mathrm{Sr}$ isotope systematics of the Gulf of Mexico (Xu and Marcantonio, 2004). More specifically, Xu and Marcantonio (2004) showed, using the sequential extraction procedure of Tessier et al. (1979) that the sediment's residual fraction is the chief reservoir (70-87\%) of Sr, and further, that $\mathrm{Sr}$ isotope ratios become more radiogenic with successive leaching from the exchangeable to the residual fraction. Nevertheless, it is well known that sequential extraction techniques are subject to artifacts that result from incomplete dissolution, re-adsorption, and non-selectivity of the extractant solutions, prompting caution when interpreting the results (Sholkovitz, 1989).

Although only one sediment sample was analyzed in this study, the results from $\mathrm{Xu}$ and Marcantonio (2004) showed consistency in the distribution of $\mathrm{Sr}$ and $\mathrm{Fe}$ between the different operationally defined fractions for all three samples they analyzed, which suggests consistency in REE distribution. Similar to Sr, majority of the REE (43-66\%) are contained within the non-labile, residual silicate mineral phases of the Mississippi River sediment. These likely include secondary clay minerals (e.g., kaolinite) and resistant accessory minerals like zircon (Armstrong-Altrin et al., 2015; Armstrong-Altrin and MachainCastillo, 2016), as well as primary minerals like muscovite and feldspars. In contrast to $\mathrm{Sr}, \mathrm{Sm} / \mathrm{Nd}$ ratios decrease with successive leaching from the exchangeable to the residual fraction (Table 4; Figure 6), which suggests that ${ }^{143} \mathrm{Nd} /{ }^{144} \mathrm{Nd}$ ratios become less radiogenic with successive leaching. The sediment's labile REE fractions (34-57\%) may become mobilized by changes in solution ionic strength, $\mathrm{pH}$, and redox conditions, all of which are characteristic of estuaries. For example, although the readily exchangeable fraction accounts for much less than $1 \%$ by weight of the total REE content of each REE (e.g., $326 \mathrm{nmol} \mathrm{kg}{ }^{-1}$ for $\mathrm{Nd}$ ) in the Mississippi riverbank sediment (Table 4), this fraction has $\mathrm{Nd}$ concentration nearly 1800 times higher than that of the Mississippi River water (184 $\mathrm{pmol} \mathrm{kg}^{-1}$ for $\mathrm{Nd}$ ). Hence, REE release from labile fractions of the river sediments and/or SPM at the estuary will likely substantially influence the REE geochemistry of the Gulf of Mexico.

Water column profiles at two sampling locations on the Louisiana Shelf (i.e., locations 6 and 10 in Figure 1) show that REE concentrations generally decrease from surface waters to mid depths $(\sim 6-10 \mathrm{~m})$, before increasing near the sea bottom (Figure 7). The HREE exhibit greater decreases to these mid depths, as well as greater relative increases from mid depths to the sea bottom, compared to the LREE. For example, at sampling location 6, Lu shows a ca. 35\% decrease in concentration (4.0$2.5 \mathrm{pmol} \mathrm{kg}{ }^{-1}$ ) at mid depth, before a ca. $29 \%$ increase in concentration near the bottom $(2.5-3.3 \mathrm{pmol} \mathrm{kg}-1)$, whereas $\mathrm{Nd}$ shows a ca. $25 \%$ decrease $\left(90-68 \mathrm{pmol} \mathrm{kg}^{-1}\right)$ at mid depth, and only a ca. $5 \%$ increase $\left(68-71 \mathrm{pmol} \mathrm{kg}^{-1}\right)$ near the bottom. The generally higher dissolved REE concentrations in the deep samples may be attributed to dissolution of the labile mineral phases within the resuspended sediments, or possibly a benthic REE flux into the water column (Nozaki et al., 2000; Haley et al., 2004; Lawrence and Kamber, 2006; Abbott et al., 2015).

To summarize, a combination of factors (i.e., higher $\mathrm{pH}$, lower REE concentrations, and solution complexation; Figure 5) may be responsible for the apparent lower REE removal in the low salinity region of the Mississippi River estuary, as compared to other major estuaries (Figure 4A). However, without additional data we cannot unequivocally rule out the possibility that this apparent stability of REE across the salinity gradient is a complex response to secondary REE source(s) within the shallow Louisiana Shelf (Figure 4B). Although we acknowledge the spatial and temporal limitations of the sampling in our study, which introduce some uncertainties in our interpretations, our data present an important finding about REE stability in the Mississippi River estuary. This study begins the process to better understand the influence of the Mississippi River estuary on the REE systematics of the Gulf of Mexico. Hence, we suggest that detailed investigations of REE in the Mississippi River estuary and estuaries of other high $\mathrm{pH}$ major rivers (e.g., Changjiang, $\mathrm{pH}$ 7.8; Huanghe, $\mathrm{pH}$ 8.3; Ganges, $\mathrm{pH}$ 7.7; Indus, $\mathrm{pH}$ 7.8; Mackenzie, pH 8.1; St. Lawrence, pH 8; Gaillardet et al., 2003) should be undertaken, to investigate whether REE stability in the estuaries of alkaline rivers is a feature common to these systems or an anomaly characteristic of the Mississippi River.

\section{Impact of Mississippi River on Nd Isotopes in the Gulf of Mexico}

A remarkable feature of the new $\varepsilon_{\mathrm{Nd}(0)}$ data for the Mississippi River in this study (Table 5) is that they are identical to the $\mathrm{Nd}$ isotope composition of similarly filtered river water (0.4 vs. 


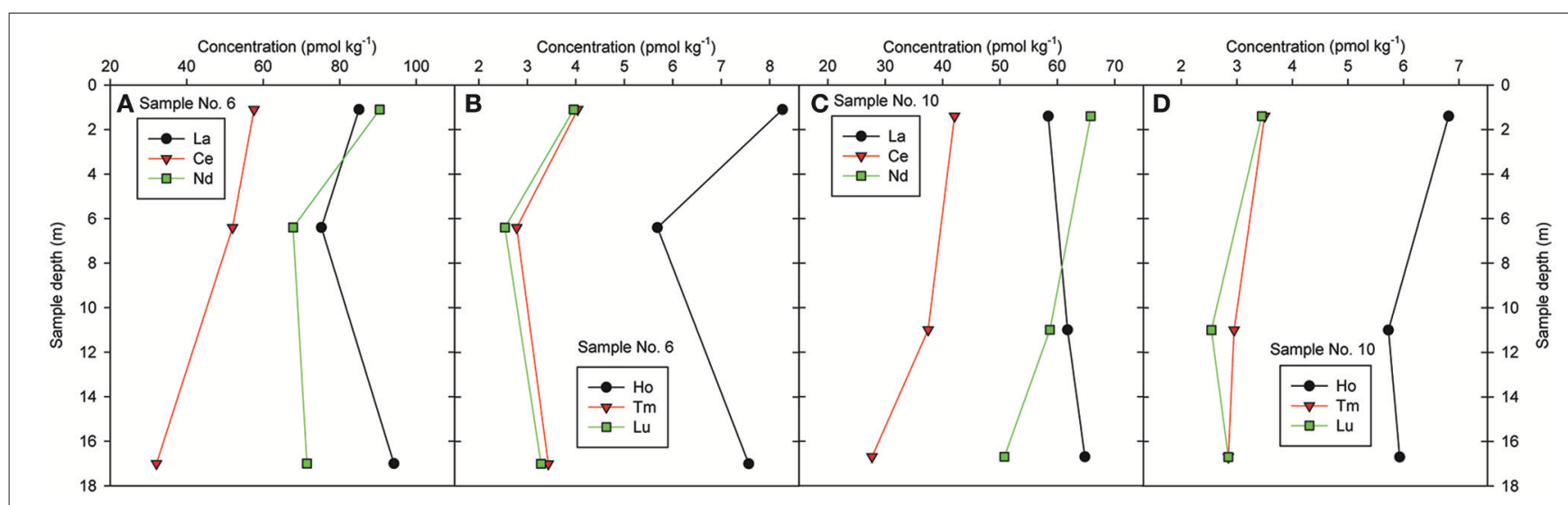

FIGURE 7 | Depth profiles of REE concentrations for samples No. 6 and 10 in the Louisiana Bight (details in Table 1) for selected REE, (A,C) LREE: La, Ce, Nd, and (B,D) HREE: Ho, Tm, Lu.

$0.45 \mu \mathrm{m}$ filters in this study) collected and analyzed more than 30 years ago from the same location (Stordal and Wasserburg, 1986). An identically filtered river water sample from Venice, Louisiana exhibited a less radiogenic $\varepsilon_{\mathrm{Nd}(0)}$ value (i.e., $-12.1 \pm$ 0.5 ), and a river water sample that was filtered through a smaller pore size filter $(0.1 \mu \mathrm{m})$ also had an $\varepsilon_{\mathrm{Nd}(0)}$ value of $-12.1 \pm 0.5$ (Stordal and Wasserburg, 1986). The $\varepsilon_{\mathrm{Nd}(0)}$ of the acid leachable fraction of SPM from the lower Mississippi River (i.e., mean ca. $-9.9)$ is also more radiogenic than $\varepsilon_{\mathrm{Nd}(0)}$ of bulk river sediment collected nearby (-10.9; Goldstein et al., 1984), as well as the silt and clay fraction of sediment collected at the river mouth $(-12.8$ and -10.8 , respectively; Bayon et al., 2015). The other published $\varepsilon_{\mathrm{Nd}(0)}$ analyses of SPM from the Mississippi River are from near the river's headwaters in Minnesota $\left[\varepsilon_{\mathrm{Nd}(0)}=-19.4\right]$, and from the river in Illinois $\left[\varepsilon_{\mathrm{Nd}(0)}=-10.1\right]$. The $\varepsilon_{\mathrm{Nd}(0)}$ values of SPM from the river in Minnesota and Illinois clearly reflect the age and $\mathrm{Nd}$ isotope composition of the underlying rocks in each region (Goldstein and Jacobsen, 1988a,b).

Figure 8 shows the locations of water column profiles within the Gulf of Mexico where Osborne et al. $(2014,2015)$ measured $\mathrm{Nd}$ isotope compositions and REE concentrations (REE only for St. 182-1). To the best of our knowledge, water column $\varepsilon_{\mathrm{Nd}(0)}$ and REE concentrations data for other locations in the Gulf are not available in peer-reviewed literature. From the mean and standard error of the $\varepsilon_{\mathrm{Nd}(0)}$ measured in the water column (Osborne et al., 2014), the seawater appears to become slightly more radiogenic between the Yucatan Straits $(-9.37 \pm 0.69 ; n$ $=4$; St. 166-1), the eastern Gulf $(-8.92 \pm 0.38$; $n=6$; St. 19413), and the Florida Straits $(-9.08 \pm 0.27 ; n=10$; St. 200-2) as it moves through the Gulf of Mexico (Figure 9). Both the mean and standard error were weighted by the inverse of measurement standard deviations. Gulf of Mexico waters, and in particular, shallow waters from the eastern Gulf (Stations 194-13 and 200-2), are more radiogenic than Mississippi River water (-10.5, up to 3 $\varepsilon_{\mathrm{Nd}}$ units), as well as SPM and sediments from the river (Table 5; Figure 9). Hence, the relatively radiogenic surface waters of the eastern Gulf cannot be chiefly composed of Mississippi River water.
Furthermore, despite substantial portions of the Gulf being covered with clastic sediments sourced from the Mississippi River (Figure 8; Trefry and Shokes, 1981), the limited $\varepsilon_{\mathrm{Nd}(0)}$ data for Mississippi River sediments (e.g., Goldstein et al., 1984; Bayon et al., 2015) indicate that these materials are likely to be substantially less radiogenic (as much as $5 \varepsilon_{\mathrm{Nd}}$ units) than eastern Gulf, as well as Mississippi River waters (Table 5; Osborne et al., 2014). Although, the $\varepsilon_{\mathrm{Nd}(0)}( \pm 2 \sigma)$ values for some of the deep waters overlap with the $\varepsilon_{\mathrm{Nd}(0)}$ value reported for Mississippi River clay (Table 5; Figure 9; Bayon et al., 2015). Hence, the Nd isotopic composition of waters in the Gulf are likely impacted by contributions from radiogenic source(s) associated with the Florida peninsula (Figure A1 in Osborne et al., 2014). Other potential radiogenic sources include materials from young mafic and intermediate volcanic rocks in the vicinity of Veracruz, Mexico, which make up substantial portions of the continental shelf and deep sea sediments in the southwestern Gulf of Mexico (Armstrong-Altrin et al., 2015; Armstrong-Altrin and MachainCastillo, 2016).

The labile fraction of SPM collected in this study exhibits the most radiogenic $\varepsilon_{\mathrm{Nd}(0)}$ values (i.e., $-9.95 \pm 0.1,-9.77$ \pm 0.23 ) reported for the lower Mississippi River, and these values are distinct $( \pm 2 \sigma)$ from Mississippi River waters (Table 5; Figure 9). Furthermore, we note that the $\mathrm{Sm} / \mathrm{Nd}$ ratios of Mississippi riverbank sediment are highly variable, ranging from 0.18 for the residual fraction to a high of 0.5 for the readily exchangeable fraction (Table 4). Recasting these $\mathrm{Sm} / \mathrm{Nd}$ ratios as approximate ${ }^{147} \mathrm{Sm} /{ }^{144} \mathrm{Nd}$ ratios using the conversion ${ }^{147} \mathrm{Sm} /{ }^{144} \mathrm{Nd}=0.6049 \times$ weight ratio of $\mathrm{Sm} / \mathrm{Nd}$ (Goldstein et al., 1984; DePaolo, 1988), leads to estimates of ${ }^{147} \mathrm{Sm} /{ }^{144} \mathrm{Nd}$ that range from 0.11 for the residual fraction to 0.35 for the exchangeable fraction (Table 4). The estimated ${ }^{147} \mathrm{Sm} /{ }^{144} \mathrm{Nd}$ values of the different fractions of Mississippi riverbank sediment are consistent with the notion that the labile portions of the riverbank sediment are more radiogenic than the bulk sediment. These observations are also consistent with the measured $\varepsilon_{\mathrm{Nd}(0)}$ values of the labile fraction of the SPM. 


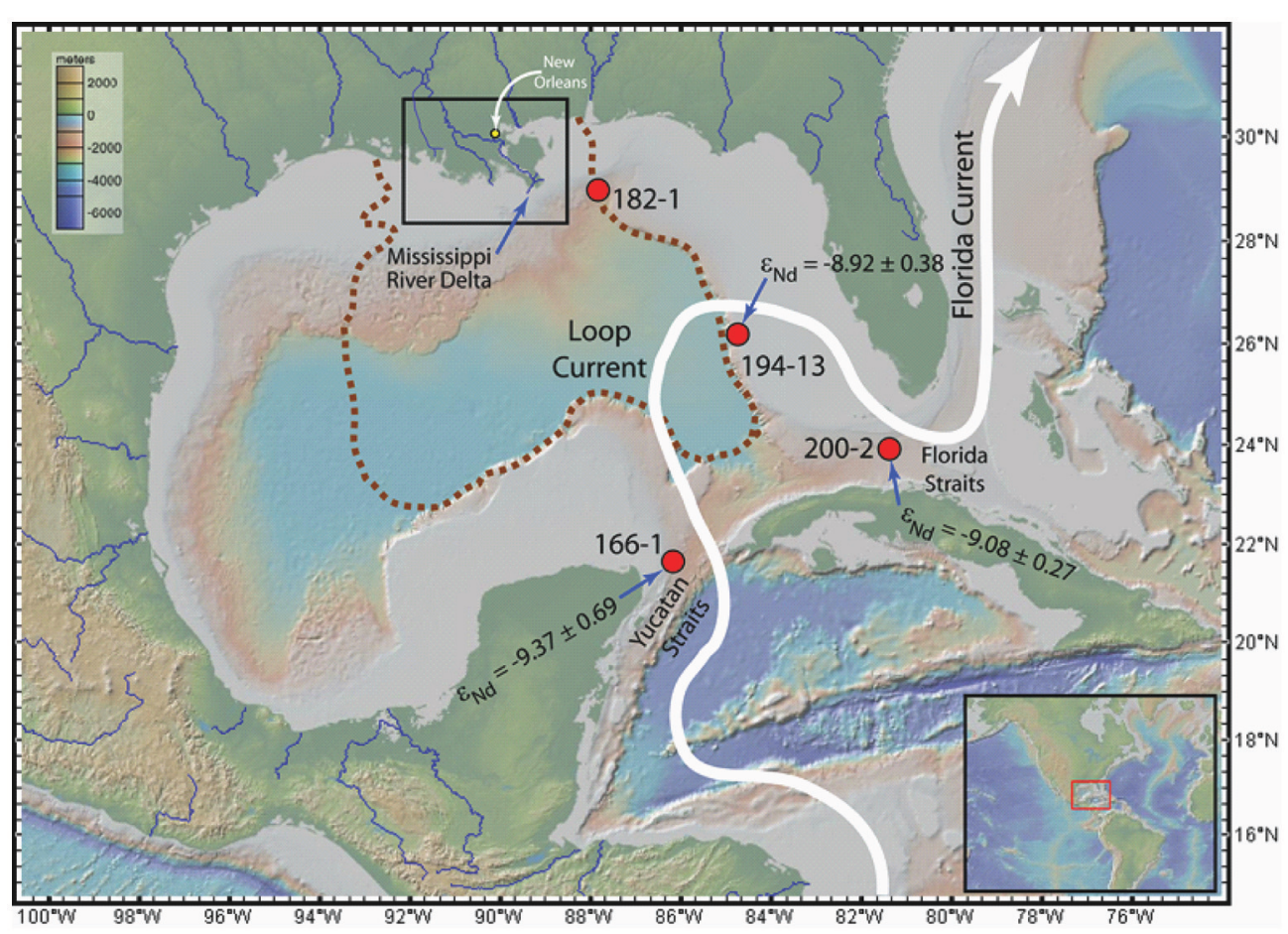

FIGURE 8 | Map of the Gulf of Mexico showing the locations of water column profiles (red circles) for REE and $\varepsilon_{\mathrm{Nd}(0)}$ from Osborne et al. (2014, 2015), the Gulf region subject to deposition of Mississippi River sediment (brown dashed line; Trefry and Shokes, 1981), and generalized track of the Loop Current (thick white arrow). The study area (black rectangle around the MR delta) is shown in more details in Figure 1. The mean and standard error (see text for details) of the $\varepsilon_{\mathrm{Nd}}(0)$ measured in the water column in the Yucatan Straits, the eastern Gulf, and the Florida Straits (Osborne et al., 2014).

It was recently argued, that rapid exchange of $\mathrm{Nd}$ between river waters and SPM leads to isotope equilibration, between the dissolved and sorbed fractions in the Amazon River estuary (Rousseau et al., 2015). A comparison of the Mississippi River waters and bulk sediments to the more radiogenic labile fraction of its SPM (Table 5), indicates that isotope equilibration between dissolved and sorbed fractions does not describe $\mathrm{Nd}$ behavior in the lower Mississippi River. Rousseau et al. (2015) argued that dissolution of relatively non-radiogenic Amazon River SPM, and/or sediments, occurred within the estuary, which was responsible for lowering the $\varepsilon_{\mathrm{Nd}(0)}$ values of the dissolved phase by about $2 \varepsilon_{\mathrm{Nd}}$ units to $\mathrm{Nd}$ isotope values more similar to the river sediments. Although our dataset is currently insufficient to unequivocally evaluate whether similar processes might also occur within the Mississippi River estuary, the existing data suggest that the labile $\mathrm{Nd}$ fraction of SPM in the Mississippi River is more radiogenic than the dissolved fraction (Table 5). Hence, exchange of $\mathrm{Nd}$ between Mississippi River water and SPM should lead to higher $\varepsilon_{\mathrm{Nd}(0)}$ values in the estuary waters, and not a decrease in $\varepsilon_{\mathrm{Nd}(0)}$ values as reported for the Amazon River estuary. Such exchange of more radiogenic Nd from SPM to the dissolved phase may help to explain the generally more radiogenic values of the Gulf of Mexico waters.

Ideally, it would be beneficial to develop a mass balance model for Nd in the Gulf of Mexico to quantitatively assess the importance of the Mississippi River on the $\varepsilon_{\mathrm{Nd}(0)}$ composition of the Gulf. However, considering the paucity of $\mathrm{Nd}$ isotope data that currently exists for the Gulf of Mexico, it seems unlikely that forward or inverse modeling (e.g., Singh et al., 2012) could provide meaningful information to help identify sources or sinks of Nd in the Gulf. Besides the Mississippi River system, the $\mathrm{Nd}$ budget of the Gulf of Mexico is also likely impacted by other rivers that discharge to the Gulf (e.g., $>40$ major estuarine systems occur within the Gulf; Wen et al., 1999), benthic porewater fluxes, submarine groundwater discharge (SGD), and/or atmospheric deposition. Although Johannesson et al. (2011) and Chevis et al. (2015) demonstrated that SGD is an important source of REE to Florida's Atlantic coastal waters, to the best of our knowledge no studies have examined REE or $\mathrm{Nd}$ isotopes in SGD entering the Gulf. Hence, the possibility of ascertaining the potential importance of SGD fluxes of REE and $\mathrm{Nd}$ isotope to the Gulf of Mexico awaits future study. Similar arguments can be made for the research gap on REE fluxes from the other rivers discharging to the Gulf, as well as benthic porewater fluxes. Hence, more sampling of the Gulf of Mexico is necessary to address the possible contributions of these and other sources.

\section{CONCLUSIONS}

Two outstanding features of the Mississippi River estuary are apparent lower REE removal at low salinity, compared to other major estuaries studied to date, and the "spike" in REE concentrations at mid to high salinity on the Louisiana Shelf. 


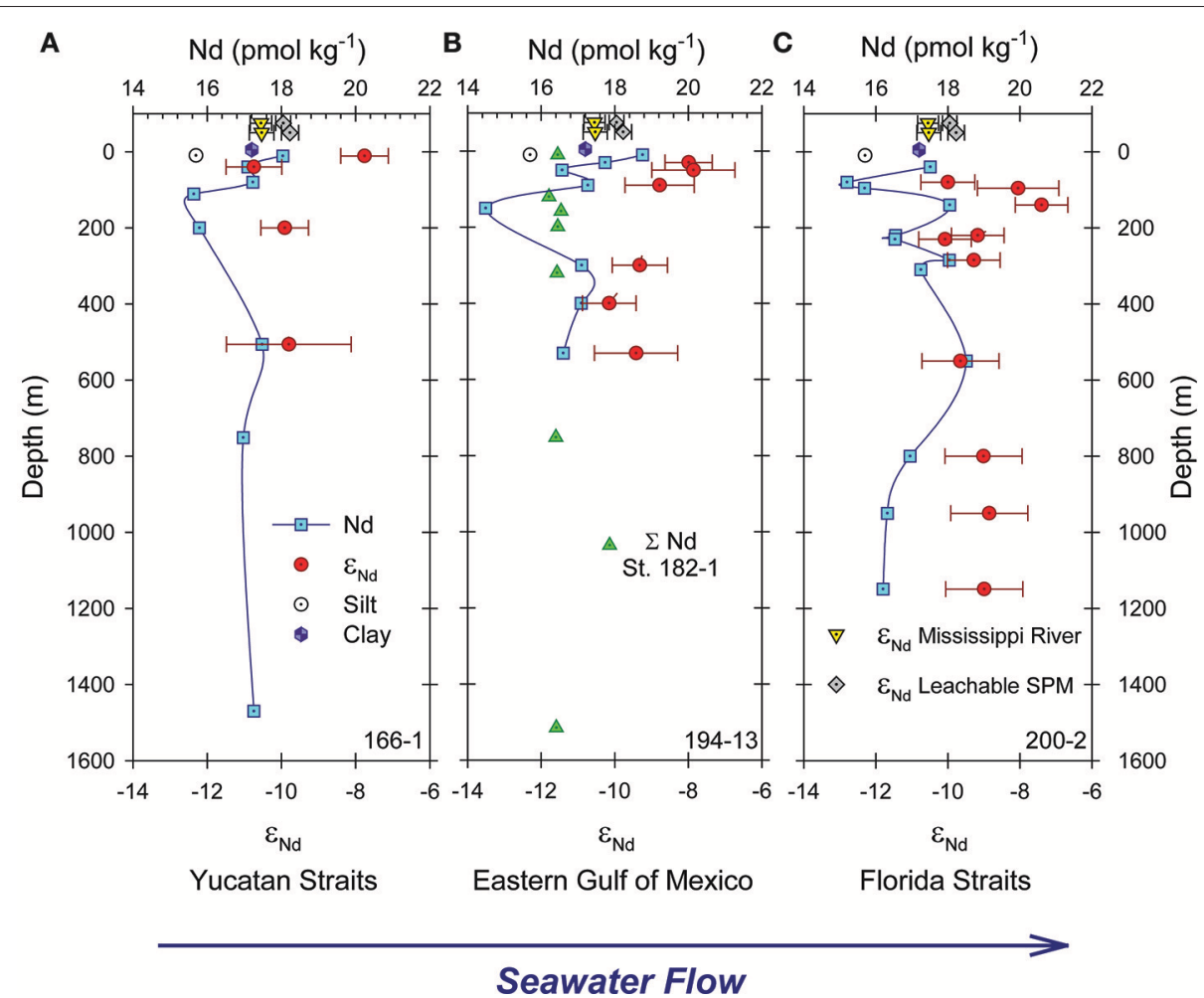

FIGURE 9 | Neodymium concentrations (blue squares) and $\varepsilon_{\text {Nd(0) }}$ (red circles) for water column samples from stations 166-1, 194-13, and 200-2 shown in Figure 8 (data from Osborne et al., 2014, 2015). Green triangles in (B) are Nd concentrations for station 182-1 (Figure 8; Osborne et al., 2015). Yellow inverted triangles and gray diamonds plotted above $0 \mathrm{~m}$ depth in each panel are $\varepsilon_{\mathrm{Nd}(0)} \pm 2 \sigma$ for Mississippi River (MR) water and the labile fraction of the associated SPM, respectively, measured in this study (Table 5). The open circle and purple hexagon show $\varepsilon_{\mathrm{Nd}(0)}$ values for the silt and clay fractions of sediments at the mouth of the MR (Bayon et al., 2015).

Only ca. $50 \%$ of river borne $\mathrm{Nd}$ is removed from solution in the Mississippi River estuary compared to ca. $97 \%$ in the Amazon estuary, and $70 \%$ for many other estuaries. Rare earth elements removal is attributed to flocculation, followed by settling out of colloids as the fresh river water and the more saline Gulf of Mexico water mix. Strong aqueous complexation of REE with natural organic ligands and carbonate ions in the alkaline $(\mathrm{pH}$ $\sim 8$ ) Mississippi River water may explain the diminished removal of the REE. Alternatively, low REE concentrations, which is a consequence of the river's alkaline $\mathrm{pH}$, may also play a role. The mechanism(s) responsible for REE "spike" at mid to high salinity in the estuary remains unclear at this point, but may be related to sediment resuspension on the shallow Louisiana Shelf.

Mississippi River water from near the river's mouth is less radiogenic than Gulf of Mexico water $\left[\varepsilon_{\mathrm{Nd}(0)}=-10.5\right.$ compared to -9.0 , respectively]. The river water exhibits $\mathrm{Nd}$ isotope compositions that are similar to or more radiogenic than bulk Mississippi River sediments. The Nd isotope composition values of the labile fraction of SPM collected from the river waters are the most radiogenic values reported for the lower Mississippi River [i.e., $\varepsilon_{\mathrm{Nd}(0)}=-9.9$ ]. Sequential leaching of Mississippi River sediment reveals that $\mathrm{Sm} / \mathrm{Nd}$ ratios decrease with successive leaching from the highly labile, exchangeable fraction, to the residual, chiefly silicate mineral fraction. These observations suggest that labile fractions of Mississippi River sediment are likely more radiogenic than the bulk sediment. This assertion is supported by the $\varepsilon_{\mathrm{Nd}(0)}$ values of the labile fraction of river borne SPM. Consequently, if the Mississippi River system impacts the $\mathrm{Nd}$ isotope composition of the Gulf of Mexico, it must do so by geochemical reactions between Gulf water and the more labile fractions of the Mississippi River sediments (or SPM). Additional studies focused on the evolution of the $\mathrm{Nd}$ isotope signatures as the waters mix will help to better understand how Mississippi River water and its sediments/SPM influence the REE and $\mathrm{Nd}$ isotope compositions of the Gulf of Mexico.

\section{AUTHOR CONTRIBUTIONS}

SA participated in sample collection, preparations, analyses, modeling, and wrote most of the manuscript. MC collected samples in the Mississippi River and Louisiana Bight, and was involved in sample analyses and preparation of manuscript figures. $\mathrm{TH}$ performed sample pre-concentrations and was involved in ICP-MS analysis. CW performed statistical analysis of data and wrote discussion on this analysis. EM performed $\mathrm{Nd}$ isotopes analysis and wrote the method section on this analysis. 
$\mathrm{KJ}$ was responsible for the research design and wrote some parts of manuscript.

\section{ACKNOWLEDGMENTS}

SA wishes to thank the Department of Earth and Environmental Sciences at Tulane University for support via graduate assistantships and the Volkes Fellowship. KJ thanks Michael

\section{REFERENCES}

Abbott, A. N., Haley, B. A., and McManus, J. (2015). Bottoms up: sedimentary control of the deep North Pacific Ocean's $\varepsilon \mathrm{Nd}$ signature. Geology 43, 1035-1035. doi: 10.1130/G37114.1

Armstrong-Altrin, J. S., and Machain-Castillo, M. L. (2016). Mineralogy, geochemistry, and radiocarbon ages of deep sea sediments from the Gulf of Mexico, Mexico. J. South Am. Earth Sci. 71, 182-200. doi: 10.1016/j.jsames.2016.07.010

Armstrong-Altrin, J. S., Machain-Castillo, M. L., Rosales-Hoz, L., CarranzaEdwards, A., Sanchez-Cabeza, J. A., and Ruíz-Fernández, A. C. (2015). Provenance and depositional history of continental slope sediments in the Southwestern Gulf of Mexico unraveled by geochemical analysis. Cont. Shelf Res. 95, 15-26. doi: 10.1016/j.csr.2015.01.003

Arsouze, T., Dutay, J. C., Lacan, F., and Jeandel, C. (2009). Reconstructing the Nd oceanic cycle using a coupled dynamical-biogeochemical model. Biogeosciences 6, 2829-2846. doi: 10.5194/bg-6-2829-2009

Bau, M., and Dulski, P. (1996). Anthropogenic origin of positive gadolinium anomalies in river waters. Earth Planet. Sci. Lett. 143, 245-255. doi: 10.1016/0012-821X(96)00127-6

Bau, M., and Dulski, P. (2003). Three types of fractionation of REY: Application in geology, astrobiology, and oceanography. XIII Goldschmidt Conf. Abs. A35.

Bayon, G., Toucanne, S., Skonieczny, C., Andr,é, L., Bermell, S., Cheron, S., et al. (2015). Rare earth elements and neodymium isotopes in world river sediments revisited. Geochim. Cosmochim. Acta 170, 17-38. doi: 10.1016/j.gca.2015.08.001

Bianchi, T. S., DiMarco, S. F., Cowan J. H. Jr., Hetland, R. D., Chapman, P., Day, J. W., et al. (2010). The science of hypoxia in the Northern Gulf of Mexico: a review. Sci. Total Environ. 408, 1471-1484. doi: 10.1016/j.scitotenv.2009.11.047

Chevis, D. A., Johannesson, K. H., Burdige, D. J., Cable, J. E., Martin, J. B., and Roy, M. (2015). Rare earth element cycling in a sandy subterranean estuary in Florida, USA. Mar. Chem. 176, 34-50. doi: 10.1016/j.marchem.2015.07.003

DePaolo, D. J. (1988). Neodymium Isotope Geochemistry: An Introduction. Berlin: Springer-Verlag.

Du, J., Haley, B. A., and Mix, A. C. (2016). Neodymium isotopes in authigenic phases, bottom waters and detrital sediments in the Gulf of Alaska and their implications for paleo-circulation reconstruction. Geochim. Cosmochim. Acta 193, 14-35. doi: 10.1016/j.gca.2016.08.005

Edzwald, J. K., Upchurch, J. B., and O'Melia, C. R. (1974). Coagulation in estuaries. Environ. Sci. Technol. 8, 58-63. doi: 10.1021/es60086a003

Elderfield, H., Upstill-Goddard, R., and Sholkovitz, E. R. (1990). The rare earth elements in rivers, estuaries, and coastal seas and their significance to the composition of ocean waters. Geochim. Cosmochim. Acta 54, 971-991. doi: 10.1016/0016-7037(90)90432-K

Gaillardet, J., Dupre, B., Allegre, C. J., and Négrel, P. (1997). Chemical and physical denudation in the Amazon River Basin. Chem. Geol. 142, 141-173. doi: 10.1016/S0009-2541(97)00074-0

Gaillardet, J., Viers, J., and Dupré, B. (2003). Trace elements in river waters. Treat. Geochem. 5:605. doi: 10.1016/B0-08-043751-6/05165-3

Goldstein, S. J., and Jacobsen, S. B. (1987). The Nd and Sr isotopic systematics of river-water dissolved material: implications for the sources of $\mathrm{Nd}$ and $\mathrm{Sr}$ in seawater. Chem. Geol. 66, 245-272. doi: 10.1016/0168-9622(87) 90045-5

Goldstein, S. J., and Jacobsen, S. B. (1988a). Nd and Sr isotopic systematics of river water suspended material: implications for crustal evolution. Earth Planet. Sci. Lett. 87, 249-265. doi: 10.1016/0012-821X(88)90013-1 and Mathilda Cochran for endowing the Cochran Family Professorship at Tulane University, which helped support the sampling and geochemical analyses. In addition, KJ thanks the NSF awards OCE-0825920 and EAR-1141692, both of which also supported the sampling and geochemical analyses. We are grateful to Tanya Goehring for assistance with the XRD analysis, and Dr. Deborah Grimm for assistance with the ICP-MS analysis.
Goldstein, S. J., and Jacobsen, S. B. (1988b). Rare earth elements in river waters. Earth Planet. Sci. Lett. 89, 35-47. doi: 10.1016/0012-821X(88)90031-3

Goldstein, S. L., and Hemming, S. R. (2003). Long-lived isotopic tracers in oceanography, paleoceanography, and ice-sheet dynamics. Treat. Geochem. 6:625. doi: 10.1016/B0-08-043751-6/06179-X

Goldstein, S. L., O'nions, R. K., and Hamilton, P. J. (1984). A Sm-Nd isotopic study of atmospheric dusts and particulates from major river systems. Earth Planet. Sci. Lett. 70, 221-236. doi: 10.1016/0012-821X(84)90007-4

Greaves, M. J., Elderfield, H., and Klinkhammer, G. P. (1989). Determination of the rare earth elements in natural waters by isotope-dilution mass spectrometry. Anal. Chim. Acta 218, 265-280. doi: 10.1016/S0003-2670(00)80303-7

Haley, B. A., Klinkhammer, G. P., and McManus, J. (2004). Rare earth elements in pore waters of marine sediments. Geochim. Cosmochim. Acta 68, 1265-1279. doi: 10.1016/j.gca.2003.09.012

Jacobsen, S. B., and Wasserburg, G. J. (1980). Sm-Nd isotopic evolution of chondrites. Earth Planet. Sci. Lett., 50, 139-155. doi: 10.1016/0012-821X(80)90125-9

Jeandel, C. (2016). Overview of the mechanisms that could explain the 'Boundary Exchange'at the land-ocean contact. Phil. Trans. R. Soc. A 374:20150287. doi: 10.1098/rsta.2015.0287

Jeandel, C., Arsouze, T., Lacan, F., Techine, P., and Dutay, J. C. (2007). Isotopic $\mathrm{Nd}$ compositions and concentrations of the lithogenic inputs into the ocean: a compilation, with an emphasis on the margins. Chem. Geol. 239, 156-164. doi: 10.1016/j.chemgeo.2006.11.013

Jeandel, C., and Oelkers, E. H. (2015). The influence of terrigenous particulate material dissolution on ocean chemistry and global element cycles. Chem. Geol. 395, 50-66. doi: 10.1016/j.chemgeo.2014.12.001

Johannesson, K. H., and Burdige, D. J. (2007). Balancing the global oceanic neodymium budget: evaluating the role of groundwater. Earth Planet. Sci. Lett. 253, 129-142. doi: 10.1016/j.epsl.2006.10.021

Johannesson, K. H., Chevis, D. A., Burdige, D. J., Cable, J. E., Martin, J. B., and Roy, M. (2011). Submarine groundwater discharge is an important net source of light and middle REEs to coastal waters of the Indian River Lagoon, Florida, USA. Geochim. Cosmochim. Acta 75, 825-843. doi: 10.1016/j.gca.2010. 11.005

Johannesson, K. H., Palmore, C. D., Fackrell, J., Prouty, N. G., Swarzenski, P. W., Chevis, D. A., ., et al. (2017). Rare earth element behavior during groundwaterseawater mixing along the Kona Coast of Hawaii. Geochim. Cosmochim. Acta 198, 229-258. doi: 10.1016/j.gca.2016.11.009

Johannesson, K. H., Tang, J., Daniels, J. M., Bounds, W. J., and Burdige, D. J. (2004). Rare earth element concentrations and speciation in organic-rich blackwaters of the Great Dismal Swamp, Virginia, USA. Chem. Geol. 209, 271-294. doi: 10.1016/j.chemgeo.2004.06.012

Kamenov, G. D., Perfit, M. R., Mueller, P. A., and Jonasson, I. R. (2008). Controls on magmatism in an island arc environment: study of lavas and sub-arc xenoliths from the Tabar-Lihir-Tanga-Feni island chain, Papua New Guinea. Contr. Mineral. Petrol. 155, 635-656. doi: 10.1007/s00410-007-0262-0

Kim, K. H., Byrne, R. H., and Lee, J. H. (1991). Gadolinium behavior in seawater: a molecular basis for gadolinium anomalies. Mar. Chem. 36, 107-120. doi: 10.1016/S0304-4203(09)90057-3

Klungness, G. D., and Byrne, R. H. (2000). Comparative hydrolysis behavior of the rare earths and yttrium: the influence of temperature and ionic strength. Polyhedron 19, 99-107. doi: 10.1016/S0277-5387(99)00332-0

Lacan, F., and Jeandel, C. (2001). Tracing Papua New Guinea imprint on the central Equatorial Pacific Ocean using neodymium isotopic compositions 
and Rare Earth Element patterns. Earth Planet. Sci. Lett. 186, 497-512. doi: 10.1016/S0012-821X(01)00263-1

Landing, W. M., and Lewis, B. L. (1991). Collection, processing, and analysis of marine particulate and colloidal material for transition metals. Marine Particles 63, 263-272. doi: 10.1029/GM063p0263

Laukert, G., Frank, M., Bauch, D., Hathorne, E. C., Gutjahr, M., Janout, M., et al. (2017). Transport and transformation of riverine neodymium isotope and rare earth element signatures in high latitude estuaries: a case study from the Laptev Sea. Earth Planet. Sci. Lett. 477, 205-217. doi: 10.1016/j.epsl.2017.08.010

Lawrence, M. G., and Kamber, B. S. (2006). The behaviour of the rare earth elements during estuarine mixing-revisited. Mar. Chem. 100, 147-161. doi: 10.1016/j.marchem.2005.11.007

Luo, Y. R., and Byrne, R. H. (2000). The ionic strength dependence of rare earth and yttrium fluoride complexation at 25 C. J. Solution Chem. 29, 1089-1099. doi: 10.1023/A:1005186932126

Luo, Y. R., and Byrne, R. H. (2001). Yttrium and rare earth element complexation by chloride ions at 25C. J. Solution Chem. 30, 837-845. doi: 10.1023/A:1012292417793

Luo, Y. R., and Byrne, R. H. (2004). Carbonate complexation of yttrium and the rare earth elements in natural waters1. Geochim. Cosmochim. Acta 68, 691-699. doi: 10.1016/S0016-7037(03)00495-2

Marsac, R., Banik, N. L., Lützenkirchen, J., Catrouillet, C., Marquardt, C. M., and Johannesson, K. H. (2017). Modeling metal ion-humic substances complexation in highly saline conditions. Appl. Geochem. 79, 52-64. doi: 10.1016/j.apgeochem.2017.02.004

McKee, B. A., Aller, R. C., Allison, M. A., Bianchi, T. S., and Kineke, G. C. (2004). Transport and transformation of dissolved and particulate materials on continental margins influenced by major rivers: benthic boundary layer and seabed processes. Cont. Shelf Res. 24, 899-926. doi: 10.1016/j.csr.2004.02.009

McLennan, S. M. (1989). Rare earth elements in sedimentary rocks; influence of provenance and sedimentary processes. Rev. Mineral. Geochem. 21, 169-200.

Merschel, G., Bau, M., and Dantas, E. L. (2017). Contrasting impact of organic and inorganic nanoparticles and colloids on the behavior of particle-reactive elements in tropical estuaries: an experimental study. Geochim. Cosmochim. Acta 197, 1-13. doi: 10.1016/j.gca.2016.09.041

Nozaki, Y., Lerche, D., Alibo, D. S., and Snidvongs, A. (2000). The estuarine geochemistry of rare earth elements and indium in the Chao Phraya River, Thailand. Geochim. Cosmochim. Acta 64, 3983-3994. doi: 10.1016/S0016-7037(00)00473-7

Osborne, A. H., Haley, B. A., Hathorne, E. C., Flögel, S., and Frank, M. (2014). Neodymium isotopes and concentrations in Caribbean seawater: tracing water mass mixing and continental input in a semi-enclosed ocean basin. Earth Planet. Sci. Lett. 406, 174-186. doi: 10.1016/j.epsl.2014.09.011

Osborne, A. H., Haley, B. A., Hathorne, E. C., Plancherel, Y., and Frank, M. (2015). Rare earth element distribution in Caribbean seawater: continental inputs versus lateral transport of distinct REE compositions in subsurface water masses. Mar. Chem. 177, 172-183. doi: 10.1016/j.marchem.2015. 03.013

Pearce, C. R., Jones, M. T., Oelkers, E. H., Pradoux, C., and Jeandel, C. (2013). The effect of particulate dissolution on the neodymium $(\mathrm{Nd})$ isotope and Rare Earth Element (REE) composition of seawater. Earth Planet. Sci. Lett. 369, 138-147. doi: 10.1016/j.epsl.2013.03.023

Pin, C., and Zalduegui, J. S. (1997). Sequential separation of light rare-earth elements, thorium and uranium by miniaturized extraction chromatography: application to isotopic analyses of silicate rocks. Anal. Chim. Acta 339, 79-89. doi: 10.1016/S0003-2670(96)00499-0

Pourret, O., Davranche, M., Gruau, G., and Dia, A. (2007). Organic complexation of rare earth elements in natural waters: evaluating model calculations from ultrafiltration data. Geochim. Cosmochim. Acta 71, 2718-2735. doi: 10.1016/j.gca.2007.04.001

Powell, R. T., and Wilson-Finelli, A. (2003). Importance of organic Fe complexing ligands in the Mississippi River plume. Estuar. Coast. Shelf Sci. 58, 757-763. doi: 10.1016/S0272-7714(03)00182-3

Rousseau, T. C., Sonke, J. E., Chmeleff, J., Van Beek, P., Souhaut, M., Boaventura, G., et al. (2015). Rapid neodymium release to marine waters from lithogenic sediments in the Amazon estuary. Nat. Commun. 6:7592. doi: $10.1038 /$ ncomms 8592
Schijf, J., and Byrne, R. H. (2004). Determination of SO $4 \beta 1$ for yttrium and the rare earth elements at $\mathrm{I}=0.66 \mathrm{~m}$ and $\mathrm{t}=25^{\circ} \mathrm{C}$-implications for YREE solution speciation in sulfate-rich waters1. Geochim. Cosmochim. Acta 68, 2825-2837. doi: 10.1016/j.gca.2003.12.003

Shiller, A. M. (2002). Seasonality of dissolved rare earth elements in the lower Mississippi River. Geochem. Geophys. Geosys. 3, 1-14. doi: 10.1029/2002GC000372

Shiller, A. M., and Boyle, E. A. (1991). Trace elements in the Mississippi River Delta outflow region: behavior at high discharge. Geochim. Cosmochim. Acta 55, 3241-3251. doi: 10.1016/0016-7037(91)90486-O

Sholkovitz, E. R. (1989). Artifacts associated with the chemical leaching of sediments for rare-earth elements. Chem. Geol. 77, 47-51. doi: 10.1016/0009-2541(89)90014-4

Sholkovitz, E. R. (1995). The aquatic chemistry of rare earth elements in rivers and estuaries. Aquat. Geochem. 1, 1-34. doi: 10.1007/BF01025229

Sholkovitz, E., and Szymczak, R. (2000). The estuarine chemistry of rare earth elements: comparison of the Amazon, Fly, Sepik and the Gulf of Papua systems. Earth Planet. Sci. Lett. 179, 299-309. doi: 10.1016/S0012-821X(00)00112-6

Siddall, M., Khatiwala, S., van de Flierdt, T., Jones, K., Goldstein, S. L., Hemming, S., et al. (2008). Towards explaining the $\mathrm{Nd}$ paradox using reversible scavenging in an ocean general circulation model. Earth Planet. Sci. Lett. 274, 448-461. doi: 10.1016/j.epsl.2008.07.044

Singh, S. P., Singh, S. K., Goswami, V., Bhushan, R., and Rai, V. K. (2012). Spatial distribution of dissolved neodymium and $\varepsilon N d$ in the Bay of Bengal: role of particulate matter and mixing of water masses. Geochim. Cosmochim. Acta 94, 38-56. doi: 10.1016/j.gca.2012.07.017

Stordal, M. C., and Wasserburg, G. J. (1986). Neodymium isotopic study of Baffin Bay water: sources of REE from very old terranes. Earth Planet. Sci. Lett. 77, 259-272. doi: 10.1016/0012-821X(86)90138-X

Tachikawa, K., Athias, V., and Jeandel, C. (2003). Neodymium budget in the modern ocean and paleo-oceanographic implications. J. Geophys. Res. 108:3254. doi: 10.1029/1999JC000285

Tanaka, T., Togashi, S., Kamioka, H., Amakawa, H., Kagami, H., Hamamoto, T., et al. (2000). JNdi-1: a neodymium isotopic reference in consistency with LaJolla neodymium. Chem. Geol. 168, 279-281. doi: 10.1016/S0009-2541(00)00198-4

Tang, J., and Johannesson, K. H. (2003). Speciation of rare earth elements in natural terrestrial waters: assessing the role of dissolved organic matter from the modeling approach. Geochim. Cosmochim. Acta 67, 2321-2339. doi: 10.1016/S0016-7037(02)01413-8

Tang, J., and Johannesson, K. H. (2010). Ligand extraction of rare earth elements from aquifer sediments: implications for rare earth element complexation with organic matter in natural waters. Geochim. Cosmochim. Acta 74, 6690-6705. doi: $10.1016 /$ j.gca.2010.08.028

Tepe, N., and Bau, M. (2016). Behavior of rare earth elements and yttrium during simulation of arctic estuarine mixing between glacial-fed river waters and seawater and the impact of inorganic (nano-) particles. Chem. Geol. 438, 134-145. doi: 10.1016/j.chemgeo.2016.06.001

Tessier, A., Campbell, P. G., and Bisson, M. (1979). Sequential extraction procedure for the speciation of particulate trace metals. Anal. Chem. 51, 844-851. doi: 10.1021/ac50043a017

Thurman, E. M. (1985). Organic Geochemistry of Natural Waters. Dordrecht: Martinus Nijhoff/Dr. Junk Publishers.

Tipping, E. (1994). WHAMC-a chemical equilibrium model and computer code for waters, sediments, and soils incorporating a discrete site/electrostatic model of ion-binding by humic substances. Comput. Geosci. 20, 973-1023. doi: 10.1016/0098-3004(94)90038-8

Tipping, E., Lofts, S., and Sonke, J. E. (2011). Humic Ion-Binding Model VII: a revised parameterisation of cation-binding by humic substances. Environ. Chem. 8, 225-235. doi: 10.1071/EN11016

Trefry, J. H., and Shokes, R. F. (1981). "History of heavy-metal inputs to Mississippi Delta sediments," in Elsevier Oceanography Series, Vol. 27, ed R. A. Geyer (Texas, TX: Elsevier), 193-208.

Welch, K. A., Lyons, W. B., Graham, E., Neumann, K., Thomas, J. M., and Mikesell, D. (1996). Determination of major element chemistry in terrestrial waters from Antarctica by ion chromatography. J. Chromatogr. A 739, 257-263. doi: 10.1016/0021-9673(96)00044-1 
Wen, L. S., Shiller, A., Santschi, P. H., and Gill, G. (1999). "Trace element behavior in Gulf of Mexico estuaries," in Biogeochemistry of Gulf of Mexico Estuaries eds T. S. Bianchi, J. R. Pennock, and R. R. Twilley (New York, NY: John Wiley and Sons), 303-346.

Willis, S. S., and Johannesson, K. H. (2011). Controls on the geochemistry of rare earth elements in sediments and groundwaters of the Aquia aquifer, Maryland, USA. Chem. Geol. 285, 32-49. doi: 10.1016/j.chemgeo.2011. 02.020

$\mathrm{Xu}, \mathrm{Y}$., and Marcantonio, F. (2004). Speciation of strontium in particulates and sediments from the Mississippi River mixing zone1. Geochim. Cosmochim. Acta 68, 2649-2657. doi: 10.1016/j.gca.2003.12.016
Conflict of Interest Statement: The authors declare that the research was conducted in the absence of any commercial or financial relationships that could be construed as a potential conflict of interest.

Copyright (c) 2018 Adebayo, Cui, Hong, White, Martin and Johannesson. This is an open-access article distributed under the terms of the Creative Commons Attribution License (CC BY). The use, distribution or reproduction in other forums is permitted, provided the original author(s) and the copyright owner are credited and that the original publication in this journal is cited, in accordance with accepted academic practice. No use, distribution or reproduction is permitted which does not comply with these terms. 